\title{
Pentanuclear Lanthanide Mono-organophosphates: Synthesis, Structure and Magnetism
}

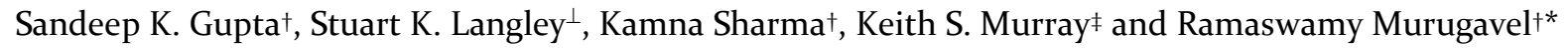 \\ ${ }^{\dagger}$ Department of Chemistry, Indian Institute of Technology Bombay, Powai, Mumbai, India. \\ ${ }^{\perp}$ School of Science and the Environment, Division of Chemistry, Manchester Metropolitan University, Manchester, \\ UK. \\ ‡ School of Chemistry, Monash University, Clayton, Victoria 380o, Australia.
}

KEYWORDS: Lanthanide organophosphates, magnetism, mono-ester of phosphoric acid, lanthanide contraction, pentanuclear clusters

Supporting Information Placeholder

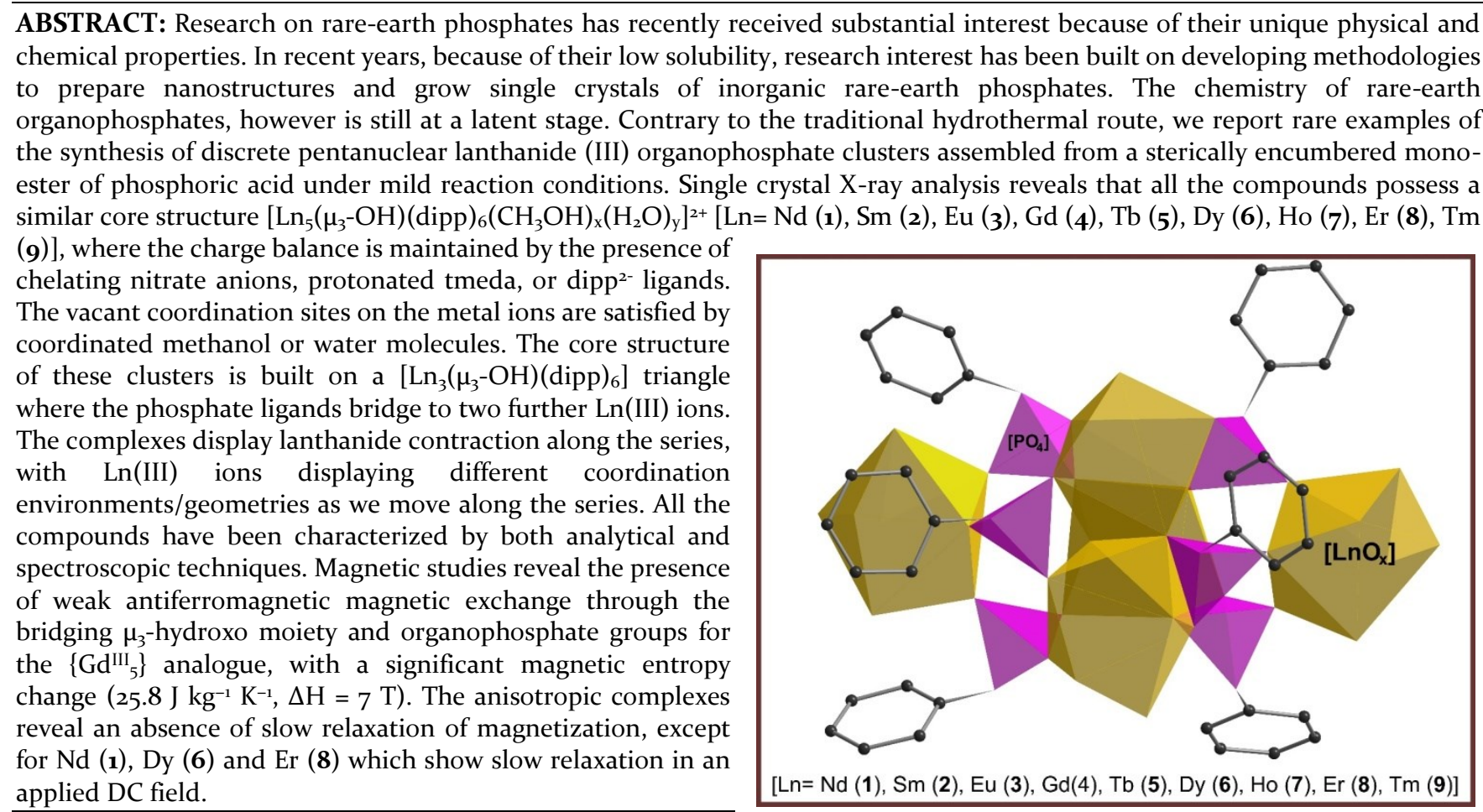

\section{Introduction}

Lanthanide coordination complexes have attracted great interest in the recent past owing to their potential applications in a wide variety of areas such as gas adsorption, ${ }^{1}$ catalysis, ${ }^{2}$ luminescence, 3 magnetic resonance imaging, 4 sensors, 5 etc. Recently there has been a huge thrust in the chemistry of rare earth complexes in view of the interesting single molecule magnet (SMM) behavior arising from the inherently large single-ion magnetic anisotropy and large ground spin state of several lanthanide ions.6,7 Furthermore,

isotropic gadolinium complexes have been investigated for their potential application as molecular coolants in the field of magnetic refrigeration. ${ }^{8}$ Although numerous ligands such as carboxylates, Schiff bases, $\beta$-ketonates, hydrazine, amine polyalcohol, macrocycles, etc. have been employed for the synthesis of rare earth complexes, the coordination chemistry of organophosphates is still to be well explored.

Research on rare-earth inorganic phosphates $\left(\mathrm{LnPO}_{4}\right)$ have been reported in recent times highlighting the capability of this class of materials for applications in diverse fields. 9 This class of material possesses some remarkable 
properties such as high thermal ${ }^{10}$ and chemical stability ${ }^{11}$, low thermal conductivity ${ }^{12}$, high refractive index, ${ }^{13}$ low water solubility ${ }^{14}$ and hydrophobicity ${ }^{15}$ among others. These unique features have led to the utilization of $\mathrm{LnPO}_{4}$ in a variety of

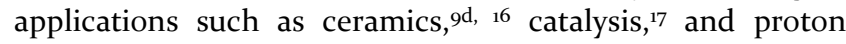
conductors. ${ }^{18}$ Further, $\mathrm{LnPO}_{4}$ has been used as a host matrix for doping with other members of the family to reveal more interesting properties such as phosphors. ${ }^{19}$ However, the low solubility of these materials prevent smooth crystallization and thus different methods have been reported to prepare single crystals of $\mathrm{LnPO}_{4}$, most recently being the stringent solvothermal route. ${ }^{20}$ One alternate method for the preparation of single crystals of lanthanide phosphates is to use the organic derivatives or esters of ortho-phosphoric acid, which aid the solubility in organic solvents and hinder fast nucleation. However, research on discrete lanthanide ion complexes derived from mono-esters of ortho-phosphoric acid are relatively unknown, although the chemistry of organophosphate ligands with transition metals has been well established. ${ }^{21,22,23}$ While organophosphates (e.g. tri-tert-butyl phosphate) have been used in the past for the extraction of lanthanides and actinides ions, ${ }^{24}$ only in very rare instances has the crystallographic structures of polymeric lanthanide organophosphate (di- or tri-esters) ${ }^{25}$ or discrete actinide complexes $^{26}$ been established. This is due to the fact that lanthanide phosphates have very low solubility products, impeding the structural characterization of this type of material. ${ }^{14}$

Examples of $4 \mathrm{f}$ and $3 \mathrm{~d}-4 \mathrm{f}$ complexes of organophosphonates (structural analogue to organophosphates) exhibiting various metallic topologies have recently been reported with some of these clusters exhibiting interesting magnetocaloric effects behaving as molecular magnetic coolants. ${ }^{27}$ In lanthanide phosphonate chemistry stringent solvothermal routes are often employed for the synthesis and growth of single crystals. ${ }^{27}$ However in the case of organophosphate esters, the situation is more complicated by the inherent ability of lanthanide ions to hydrolyze and cleave the ester $\mathrm{P}-\mathrm{O}$ bonds leading to the formation of insoluble inorganic phosphates. ${ }^{28}$ Interestingly, metal ions have also been reported to cleave the $\mathrm{P}-\mathrm{C}$ bond in the case of organophosphonates during the solvothermal reaction conditions. ${ }^{29}$ Thus, in order to prevent hydrolysis in the course of the reaction, we have precisely selected a sterically encumbered mono-ester of phosphoric acid - 2,6-diiso-propylphenyl phosphate $\left(\operatorname{dippH}_{2}\right)$, where the isopropyl group imparts additional solubility and provides a protective hydrophobic pocket near the hydrolytically susceptible -P-O bond of the ester. A preliminary account of this study, describing the isotropic Gd(III) derivative and its interesting magnetocaloric effect property has recently been reported. ${ }^{8 f}$ Building on our earlier efforts, the synthesis, structural characterization and investigation of the magnetic properties of an extended series of discrete polynuclear lanthanide complexes using the mono-ester of phosphoric acid namely dippH 2 are reported.

\section{Results and discussion Synthetic aspects}

The synthesis of lanthanide organophosphates was carried out under mild reaction conditions under an ambient aerobic atmosphere. Tetramethylethylene diamine (tmeda) was employed as the base for the deprotonation of the $-\mathrm{P}-\mathrm{OH}$ groups of the phosphate ligand, $\operatorname{dippH}_{2}$. The reaction of $\mathrm{Ln}\left(\mathrm{NO}_{3}\right)_{3} \cdot \mathrm{xH}_{2} \mathrm{O}$, with $\operatorname{dippH}_{2}$ in the presence of tmeda (1:1:2 molar ratio) in a methanolic solution at $60{ }^{\circ} \mathrm{C}$, leads to the formation of a family of pentanuclear lanthanide(III) phosphates [ $\operatorname{Ln}=\mathrm{Nd}(\mathbf{1}), \mathrm{Sm}(\mathbf{2}), \mathrm{Eu}(\mathbf{3}), \mathrm{Gd}(\mathbf{4}), \mathrm{Tb}$ (5), Dy (6), Ho (7), Er (8), Tm (9)] in quantitative yield (Scheme 1). Although the basic metal ion architecture is essentially same, small differences on the peripheral ligands result in the isolation of three unique structures as shown in Scheme 1.

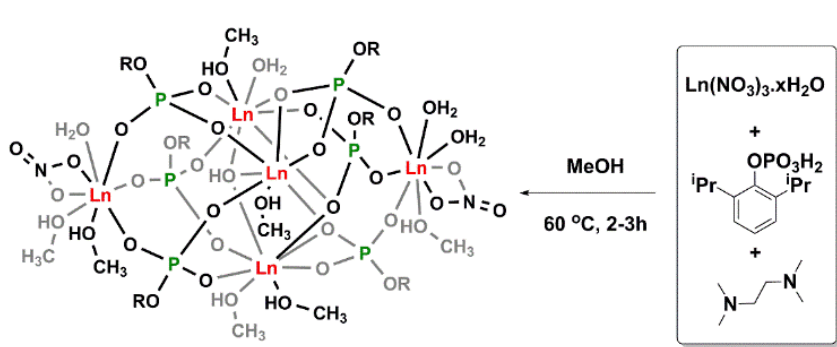

Ln = Nd (1); Sm (2); Eu (3); Gd (4); Tb (5)
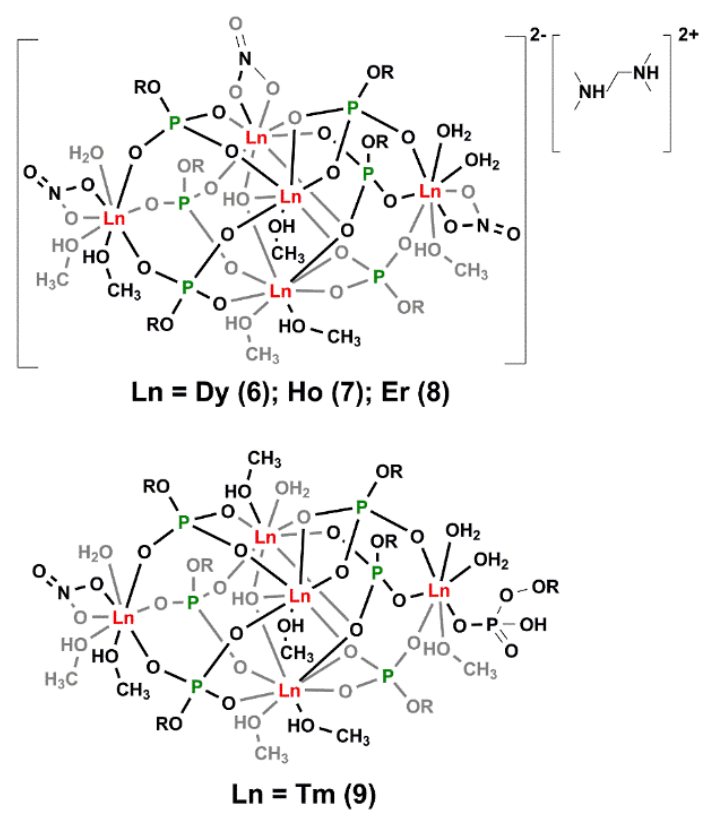

Scheme 1. Synthesis of pentanuclear lanthanide phosphates (1-9).

Single crystals of each complex were obtained via slow evaporation of the solvent. In order to obtain pure products, the reaction mixture kept for crystallization was repeatedly filtered until no precipitation was observed during 
the evaporation. The compounds were obtained as block shaped crystals from the reaction mixture in one to two weeks. The molecular structures of all the clusters have been established by single crystal X-ray diffraction studies. All the new compounds have been characterized by means of both spectroscopic and analytical techniques. The molecular composition of the compounds deduced are listed in Table 1.

Table 1. Molecular composition of the pentanuclear lanthanide phosphates (1-9).

\begin{tabular}{|c|c|}
\hline No & Molecular composition of single crystal \\
\hline 1 & {$\left[\mathrm{Nd}_{5}\left(\mu_{3}-\mathrm{OH}\right)\left(\mathrm{NO}_{3}\right)_{2}(\mathrm{dipp})_{6}\left(\mathrm{CH}_{3} \mathrm{OH}\right)_{7}\left(\mathrm{H}_{2} \mathrm{O}\right)_{4}\right] \cdot 4 \mathrm{CH}_{3} \mathrm{OH} \cdot \mathrm{H}_{2} \mathrm{O}$} \\
\hline 2 & {$\left[\mathrm{Sm}_{5}\left(\mu_{3}-\mathrm{OH}\right)\left(\mathrm{NO}_{3}\right)_{2}(\mathrm{dipp})_{6}\left(\mathrm{CH}_{3} \mathrm{OH}\right)_{7}\left(\mathrm{H}_{2} \mathrm{O}\right)_{4}\right] \cdot 5 \mathrm{CH}_{3} \mathrm{OH}$} \\
\hline 3 & {$\left[\mathrm{Eu}_{5}\left(\mu_{3}-\mathrm{OH}\right)\left(\mathrm{NO}_{3}\right)_{2}(\mathrm{dipp})_{6}\left(\mathrm{CH}_{3} \mathrm{OH}\right)_{7}\left(\mathrm{H}_{2} \mathrm{O}\right)_{4}\right] \cdot 5 \mathrm{CH}_{3} \mathrm{OH}$} \\
\hline 4 & {$\left[\mathrm{Gd}_{5}\left(\mu_{3}-\mathrm{OH}\right)\left(\mathrm{NO}_{3}\right)_{2}(\mathrm{dipp})_{6}\left(\mathrm{CH}_{3} \mathrm{OH}\right)_{7}\left(\mathrm{H}_{2} \mathrm{O}\right)_{4}\right] \cdot 5 \mathrm{CH}_{3} \mathrm{OH}^{8 f}$} \\
\hline 5 & {$\left[\mathrm{~Tb}_{5}\left(\mu_{3}-\mathrm{OH}\right)\left(\mathrm{NO}_{3}\right)_{2}(\mathrm{dipp})_{6}\left(\mathrm{CH}_{3} \mathrm{OH}\right)_{7}\left(\mathrm{H}_{2} \mathrm{O}\right)_{4}\right] \cdot 4 \mathrm{CH}_{3} \mathrm{OH} \cdot \mathrm{H}_{2} \mathrm{O}$} \\
\hline 6 & {$\left[\mathrm{Dy}_{5}\left(\mu_{3}-\mathrm{OH}\right)\left(\mathrm{NO}_{3}\right)_{3}(\mathrm{dipp})_{6}\left(\mathrm{CH}_{3} \mathrm{OH}\right)_{5}\left(\mathrm{H}_{2} \mathrm{O}\right)_{2}\right]\left[\mathrm{tmedaH}_{2}\right]_{0.5} \cdot 5 \mathrm{CH}_{3} \mathrm{OH} \cdot 2 \mathrm{H}_{2} \mathrm{O}$} \\
\hline 7 & {$\left[\mathrm{Ho}_{5}\left(\mu_{3}-\mathrm{OH}\right)\left(\mathrm{NO}_{3}\right)_{3}(\mathrm{dipp})_{6}\left(\mathrm{CH}_{3} \mathrm{OH}\right)_{5}\left(\mathrm{H}_{2} \mathrm{O}\right)_{2}\right]\left[\mathrm{tmedaH}_{2}\right]_{0.5} \cdot 5 \mathrm{CH}_{3} \mathrm{OH} \cdot 2 \mathrm{H}_{2} \mathrm{O}$} \\
\hline 8 & {$\left[\mathrm{Er}_{5}\left(\mu_{3}-\mathrm{OH}\right)\left(\mathrm{NO}_{3}\right)_{3}(\mathrm{dipp})_{6}\left(\mathrm{CH}_{3} \mathrm{OH}\right)_{5}\left(\mathrm{H}_{2} \mathrm{O}\right)_{2}\right]\left[\mathrm{tmedaH}_{2}\right]_{0.5} \cdot 5 \mathrm{CH}_{3} \mathrm{OH} \cdot 2 \mathrm{H}_{2} \mathrm{O}$} \\
\hline 9 & {$\left[\mathrm{Tm}_{5}\left(\mu_{3}-\mathrm{OH}\right)(\mathrm{dipp})_{7}\left(\mathrm{CH}_{3} \mathrm{OH}\right)_{7}\left(\mathrm{H}_{2} \mathrm{O}\right)_{2}\right]_{5} \cdot \mathrm{CH}_{3} \mathrm{OH} \cdot 3 \mathrm{H}_{2} \mathrm{O}$} \\
\hline
\end{tabular}

\section{FTIR spectroscopy and thermogravimetric analysis}

The FTIR spectra of compounds 1-9 were recorded as transparent discs that were diluted with $\mathrm{KBr}$. Compounds 1-9 don't show a broad absorption band at $\sim 2300 \mathrm{~cm}^{-1}$ in the infrared spectra indicating complete deprotonation of the phosphate ligands and hence the absence of any free $\mathrm{P}-\mathrm{OH}$ groups in the molecular structure (Figure $\mathrm{S}$ ). The strong absorption for the $\mathrm{P}=\mathrm{O}$ stretching vibrations and the symmetric and anti-symmetric $\mathrm{M}-\mathrm{O}-\mathrm{P}$ stretching vibrations are observed in the region 1100 and $1050-950 \mathrm{~cm}^{-1}$, respectively (see experimental section for details).

The stability of 1-9 has been analyzed by thermal decomposition analysis under an $\mathrm{N}_{2}$ atmosphere at a heating rate of $10{ }^{\circ} \mathrm{C} \mathrm{min}^{-1}$. All compounds reveal a similar type of weight loss (Figures S2). The first weight loss of about $10 \%$ of the sample weight, up to $200{ }^{\circ} \mathrm{C}$, is due to successive losses of lattice and coordinated solvent molecules. On further heating the sample up to $500{ }^{\circ} \mathrm{C}$, there is loss of about $35-40 \%$ of the total mass corresponding to the loss of most of the organic groups of the molecule. No major weight loss was observed between $500{ }^{\circ} \mathrm{C}$ and $800{ }^{\circ} \mathrm{C}$.

\section{Structural features of lanthanide organophosphates}

Single crystal X-ray diffraction analysis reveals that compounds 1-9 each display similar metal ion core architectures, built on a central triangle, $\left[\operatorname{Ln}_{3}\left(\mu_{3}-\mathrm{OH}\right)(\text { dipp })_{6}\right]$, where the three $\operatorname{Ln}\left(\right.$ III) ions are bridged by a $\mu_{3}$-hydroxo anion. The phosphate dianion embraces the central $\operatorname{Ln}_{3}\left(\mu_{3}-\right.$ $\mathrm{OH}$ ) unit, forming a bridge from the triangle to the two peripheral lanthanide cations. The charge balance of each complex is maintained by the presence of chelating nitrate ions (1- 8), protonated tmeda (6- 8) and a terminal dipp ${ }^{2-}$ ligand (9), the vacant coordination sites on the metal ions are satisfied by coordinated methanol or water molecules. Compounds 1-8 crystallize in the triclinic space group, $P \overline{1}$, while the thulium complex (9) crystallizes in the monoclinic space group, $P 2_{1} / n$. A summary of the crystallographic refinement details is presented in Table 5 and 6 . There are three distinct coordination environments found for this family of compounds, namely, $\mathbf{1}-\mathbf{5}, 6-8$ and 9, respectively. Representative compounds, viz. $1\left(\mathrm{Nd}^{\mathrm{III}}\right), \mathbf{6}\left(\mathrm{Dy}^{\mathrm{III}}\right)$ and $\mathbf{9}\left(\mathrm{Tm}^{\mathrm{III}}\right)$ are described in detail. The molecular structure of 4 has been described before. ${ }^{8 f}$ Compound 1 and 5 differ from 2, 3 and 4 only by a replacement of lattice methanol solvate by water molecule (compounds (1 and 5); (2, 3 and 4); (6, 7 and 8) are isomorphous).

\section{Molecular structures of 1-5}

Compounds 1-5 reveal an identical metal ion arrangement and coordination environment. All crystallize in the triclinic space group, $P \overline{1}$. Compound $\mathbf{1}$ will be described in detail. The asymmetric part of the unit cell in $\mathbf{1}$ contains five metal ions, six phosphate ligands, one $\mu_{3}-\mathrm{OH}$ and two nitrate groups at the core with coordinated methanol (seven) and water (four) molecules. In addition to this, there are four methanol and a water molecule in the crystal lattice. A perspective view of the molecular structure of $\mathbf{1}$ is shown in Figure 1. Complex $\mathbf{1}$ is therefore a discrete pentanuclear lanthanide organophosphate complex, enclosed by an organic sheath of aromatic rings around the periphery (Figure 2). Compound 1 contains a $\mu_{3}-\mathrm{OH}$ centered metal trinuclear unit, $\left[\mathrm{Nd}_{3}\left(\mu_{3}-\mathrm{OH}\right)(\operatorname{dipp})_{6}\right]$, where the three metal centers are bridged by the six phosphate ligands (Figure 3), which embrace two more metal centers at the periphery of the cluster to complete the pentanuclear trigonal bipyramidal construct (Figure 1). The average metal-oxygen distance in the trinuclear unit $\left[\mathrm{Nd}_{3}\left(\mu_{3}-\mathrm{OH}\right)\right]$ is $2.463 \AA$, whereas the average metal-metal distance is $4.017 \AA$. The distance of $\mathrm{O}_{25}$ from the mean plane of $\mathrm{Nd}_{1}, \mathrm{Nd}_{2}, \mathrm{Nd}_{3}$ is $0.832 \AA$. The angles around the $\mu_{3}-\mathrm{OH}$ oxygen atom with the metal centres are $\mathrm{Nd}_{3}-\mathrm{O}_{25}-$ $\mathrm{Nd}_{2} \cdots{ }_{109}{ }_{63}(2)^{\circ}, \mathrm{Nd}_{3}-\mathrm{O}_{25}-\mathrm{Nd}_{1} \cdots{ }_{108.96}(2)^{\circ}$ and $\mathrm{Nd}_{2}-\mathrm{O}_{25}-$ $\mathrm{Nd}_{1} \cdots 109.03(2)^{\circ}$. The core structure of the metal trinuclear unit, $\left[\mathrm{Nd}_{3}\left(\mu_{3}-\mathrm{OH}\right)(\text { dipp })_{6}\right]$ resembles the $\left[\mathrm{Ln}\left(\mu_{3}-\mathrm{OH}\right)\right]_{4}$ cubane structure with the absence of one $\operatorname{Ln}($ III) ion, as observed in other lanthanide complexes (Figure 3). ${ }^{8 \mathrm{~g},} 30$

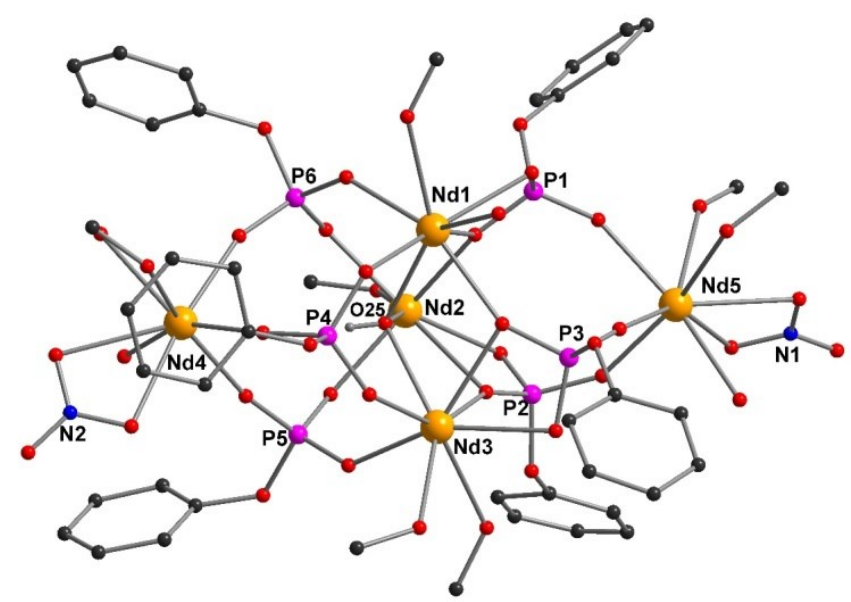

Figure 1. Molecular structure of the pentanuclear neodymium organophosphate, 1. Isopropyl groups, lattice solvates and most hydrogen atoms are removed for clarity. 


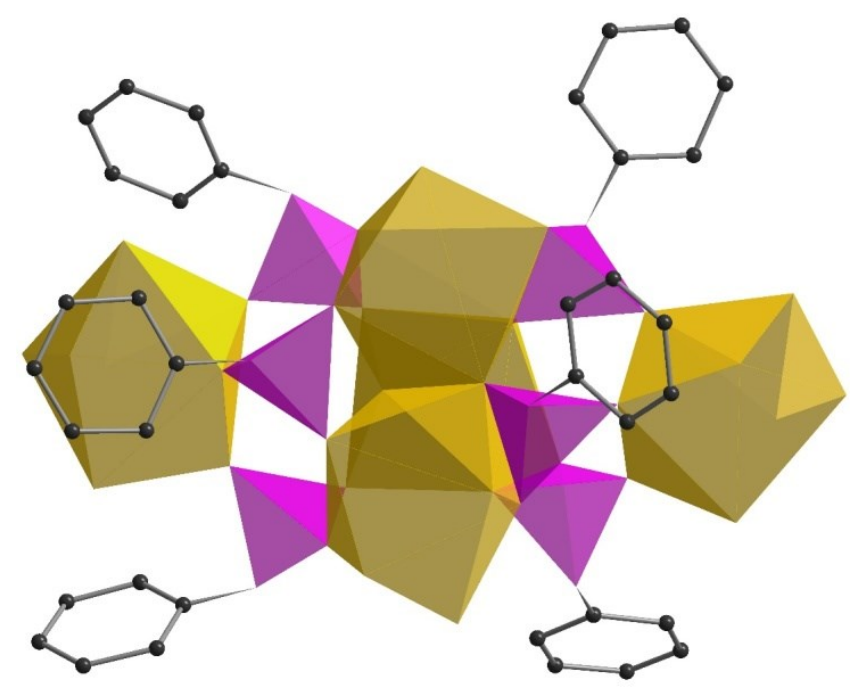

Figure 2. Polyhedral diagram showing the inorganic core wrapped within the organic part of the phosphate ligands in $\mathbf{1 .}$ Yellow and pink polyhedra represent the coordination environment of the $\mathrm{Nd}(\mathrm{III})$ ions and phosphorous atom, respectively.

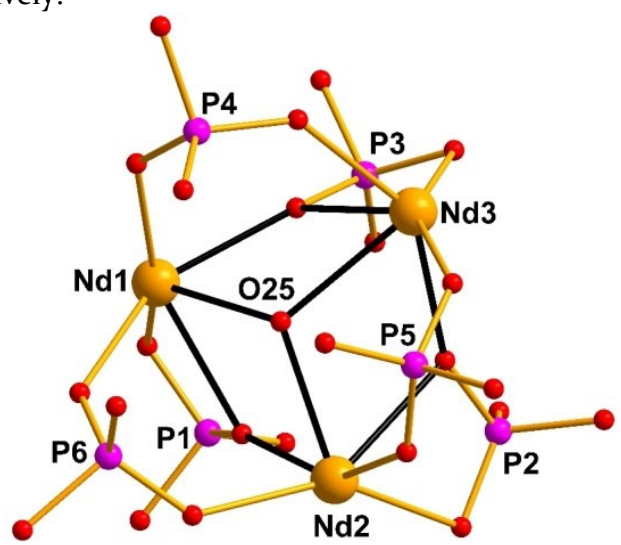

Figure 3. View of the $\left[\mathrm{Nd}_{3}\left(\mu_{3}-\mathrm{OH}\right)(\text { dipp })_{6}\right]$ triangle for $\mathbf{1}$. The organic part of the phosphate ligands has been removed for clarity.

Of the six phosphate ligands that are present there are two sets of three phosphates, each that bind to the $\operatorname{Ln}($ III)-ions in a [3.111] and [3.211] fashion, respectively (Figure 4).31 Phosphates $\mathrm{P}_{1}, \mathrm{P}_{2}$ and $\mathrm{P}_{3}$ bind, through the $\mathrm{O}$-atoms in the [3.211] fashion on one side of the complex, bridging $\mathrm{Nd}_{1}, \mathrm{Nd}_{2}$ and $\mathrm{Nd}_{3}$ with the peripheral $\mathrm{Nd}_{5}$ ion. Phosphates $\mathrm{P}_{4}, \mathrm{P}_{5}$ and P6 bind in the [3.111] fashion on the other side of the complex, bridging $\mathrm{Nd}_{1}, \mathrm{Nd}_{2}$ and $\mathrm{Nd}_{3}$ with $\mathrm{Nd}_{4}$. The metal-metal distances between the terminal and the central neodymium ions vary in the range of 5.467-5.838 A. The metal-metal distance between the two peripheral neodymium ions is 10.266(2) $\AA$. The two nitrate anions chelate to the peripheral $\mathrm{Nd}_{4}$ and $\mathrm{Nd}_{5}$ ions. The coordination spheres of the central and outer neodymium ions are completed by coordinated solvent $\left(\mathrm{MeOH}\right.$ and $\left.\mathrm{H}_{2} \mathrm{O}\right)$ molecules. Four of the neodymium atoms $\left(\mathrm{Nd}_{1}, \mathrm{Nd}_{3}, \mathrm{Nd}_{4}, \mathrm{Nd}_{5}\right)$ are eight coordinate, whereas $\mathrm{Nd}_{2}$ is seven coordinate. The coordination environment around the rare-earth metal ions were analyzed by SHAPE 2.1 software ${ }^{32}$ (Table $\mathrm{S}_{17}$ and $\mathrm{S}_{18}$ ). The $\left\{\mathrm{NdO}_{8}\right\}$ environment built around $\mathrm{Nd}_{1}, \mathrm{Nd}_{3}$ and $\mathrm{Nd}_{5}$ shows least deviation from the ideal $C_{2 v}$ symmetry occupying a distorted biaugmented trigonal prism geometry, the $\left\{\mathrm{NdO}_{8}\right\}$ environment around $\mathrm{Nd}_{4}$ shows least deviation from the ideal $D_{2 \mathrm{~d}}$ symmetry adopting a triangular dodecahedron geometry (Figure 5 ). The $\left\{\mathrm{NdO}_{7}\right\}$ environment around $\mathrm{Nd} 2$ displays a capped trigonal prismatic geometry with least deviation from the ideal $\mathrm{C}_{2} \mathrm{~V}$ symmetry (Figure 5).

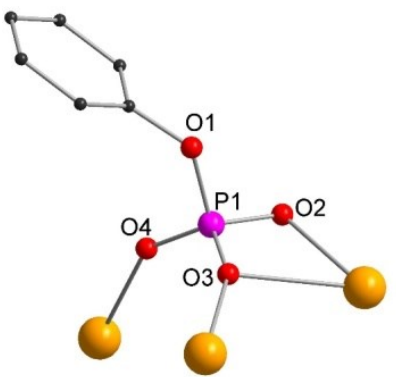

[3.211]

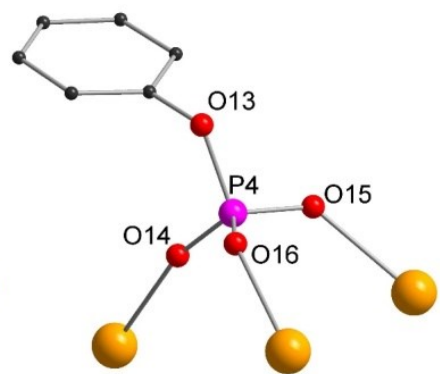

[3.111]
Figure 4. Binding mode of the phosphate ligands in $\mathbf{1 .}$ a)

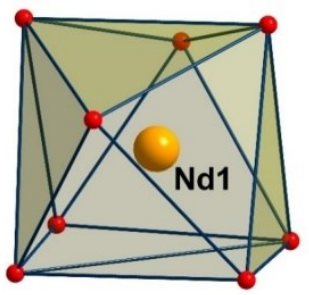

c)

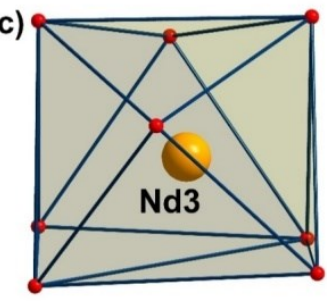

b)

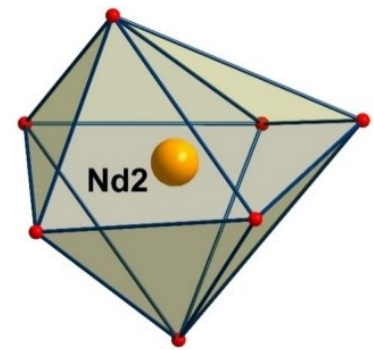

d)

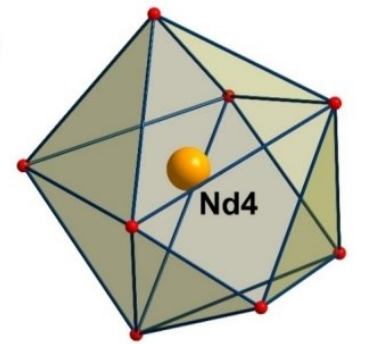

e)

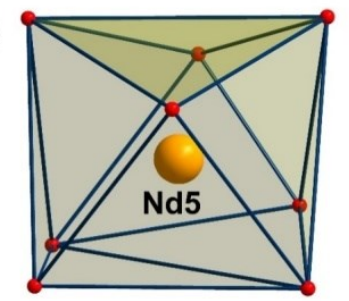

Figure 5 (a-e). Polyhedral representation of the distorted coordination geometry around the $\mathrm{Nd}$ (III) ions in the crystal structure of compound $\mathbf{1}$.

Along with the coordinated and lattice solvent molecules, the coordinated nitrate ions are involved in extensive intermolecular and intramolecular $\mathrm{H}$-bonding, leading to the formation of two-dimensional self-assembled hydrogen bonded networks of the pentanuclear complexes (Figure 6).

The structural features of 2-4 are similar to those of 1, with the metal ions displaying similar coordination environments (Table $\mathrm{S}_{2}-\mathrm{S}_{4}$ ). As we move along the series it is observed that the $\mathrm{Ln}-\mathrm{O}_{25}$ and $\mathrm{Ln} \cdots$ - Ln distances in the central triangular unit gradually decrease (Table 2 ). 


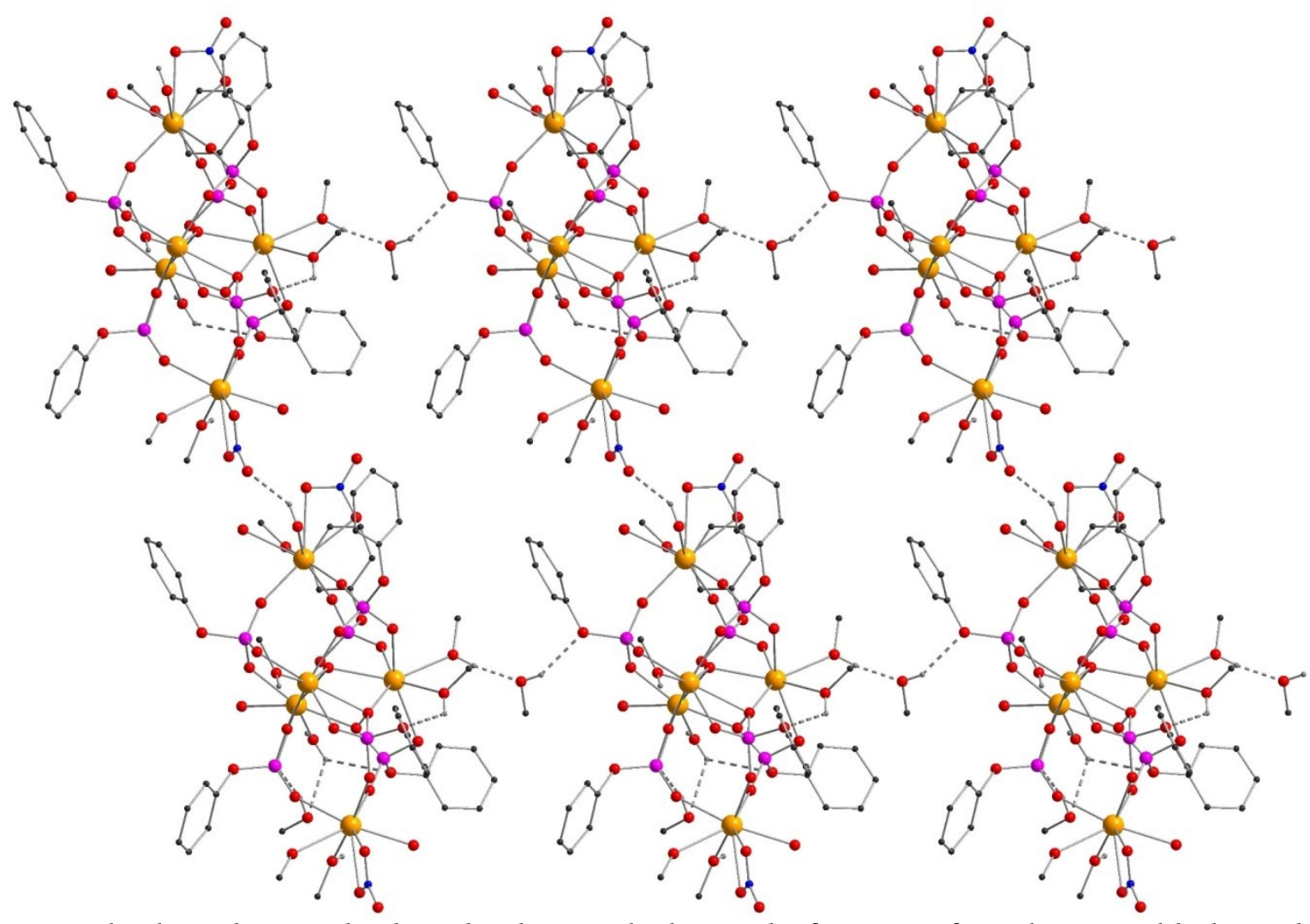

Figure 6. Intermolecular and intramolecular H-bonding in $\mathbf{1}$ leading to the formation of two-dimensional hydrogen bonded networks of the pentanuclear rare-earth phosphate complexes.

Table 2. Ln- $\mathrm{O}_{25}$ and Ln** Ln distances $(\AA)$ in the central triangular unit $\left[\operatorname{Ln}_{3}\left(\mu_{3}-\mathrm{OH}\right)(\mathrm{dipp})_{6}\right]$ in 1-9.

\begin{tabular}{|c|c|c|c|c|c|}
\hline \multicolumn{2}{|c|}{1} & \multicolumn{2}{|l|}{2} & \multicolumn{2}{|l|}{3} \\
\hline $\mathrm{Nd}_{1}-\mathrm{O}_{25}$ & $2.455(4)$ & $\mathrm{Sm}_{1}-\mathrm{O}_{25}$ & $2.421(4)$ & Eu1-O25 & $2.403(3)$ \\
\hline $\mathrm{Nd} 2-\mathrm{O}_{25}$ & $2.437(4)$ & $\mathrm{Sm} 2-\mathrm{O} 25$ & $2.403(4)$ & $\mathrm{Eu}_{2}-\mathrm{O}_{25}$ & $2.393(3)$ \\
\hline $\mathrm{Nd}_{3}-\mathrm{O}_{25}$ & $2.499(4)$ & $\mathrm{Sm}_{3}-\mathrm{O}_{25}$ & $2.474(4)$ & $\mathrm{Eu}_{3}-\mathrm{O}_{25}$ & $2.456(3)$ \\
\hline $\mathrm{Nd}_{1}-\mathrm{Nd}_{2}$ & $3.998(7)$ & Sm1-Sm2 & $3.927(7)$ & Eu1-Eu2 & $3.905(8)$ \\
\hline $\mathrm{Nd}_{1}-\mathrm{Nd}_{3}$ & $4.034(6)$ & $\mathrm{Sm}_{1}-\mathrm{Sm}_{3}$ & $3.979(6)$ & Eu1-Eu3 & $3.956(7)$ \\
\hline $\mathrm{Nd}_{2}-\mathrm{Nd}_{3}$ & $4.018(6)$ & $\mathrm{Sm}_{2}-\mathrm{Sm}_{3}$ & $3.965(6)$ & $\mathrm{Eu}_{2}-\mathrm{Eu}_{3}$ & $3 \cdot 942(7)$ \\
\hline $\mathrm{Nd}_{1}-\mathrm{O}_{25}-\mathrm{Nd} 2$ & $109.64(1)$ & $\mathrm{Sm}_{1}-\mathrm{O}_{25}-\mathrm{Sm} 2$ & $109.00(2)$ & Eu1-O25-Eu2 & $109.05(1)$ \\
\hline $\mathrm{Nd}_{1}-\mathrm{O}_{25}-\mathrm{Nd}_{3}$ & $109.03(1)$ & $\mathrm{Sm}_{1}-\mathrm{O}_{25}-\mathrm{Sm}_{3}$ & $108.71(1)$ & Eu1-O25-Eu3 & $109.03(1)$ \\
\hline $\mathrm{Nd}_{2}-\mathrm{O}_{2}-\mathrm{Nd}_{3}$ & 108.96(1) & $\mathrm{Sm}_{2}-\mathrm{O}_{25}-\mathrm{Sm}_{3}$ & $108.75(2)$ & $\mathrm{Eu}_{2}-\mathrm{O}_{25}-\mathrm{Eu}_{3}$ & $108.77(1)$ \\
\hline \multicolumn{2}{|l|}{4} & \multicolumn{2}{|l|}{5} & \multicolumn{2}{|l|}{6} \\
\hline $\mathrm{Gd}_{1}-\mathrm{O}_{25}$ & $2.398(5)$ & Tb1-O25 & $2.400(4)$ & $\mathrm{Dy}_{1}-\mathrm{O}_{25}$ & $2.365(3)$ \\
\hline $\mathrm{Gd}_{2}-\mathrm{O}_{25}$ & $2.375(5)$ & Tb2-O25 & $2.363(4)$ & Dy2-O25 & $2.340(3)$ \\
\hline $\mathrm{Gd}_{3}-\mathrm{O}_{25}$ & $2.448(5)$ & $\mathrm{Tb}_{3}-\mathrm{O}_{25}$ & $2.438(4)$ & $\mathrm{Dy}_{3}-\mathrm{O}_{25}$ & $2.390(3)$ \\
\hline Gd1-Gd2 & $3.886(8)$ & Tb1-Tb2 & $3.870(7)$ & Dy1-Dy2 & $3.820(5)$ \\
\hline $\mathrm{Gd}_{1}-\mathrm{Gd}_{3}$ & $3.940(9)$ & Tb1-Tb3 & $3.930(6)$ & Dy1-Dy3 & $3.900(5)$ \\
\hline $\mathrm{Gd}_{2}-\mathrm{Gd}_{3}$ & $3.919(8)$ & $\mathrm{Tb}_{2}-\mathrm{Tb}_{3}$ & $3.898(6)$ & Dy2-Dy3 & $3.852(4)$ \\
\hline $\mathrm{Gd}_{2}-\mathrm{O}_{25}-\mathrm{Gd}_{1}$ & $109.02(2)$ & Tb1-O25-Tb2 & $108.68(1)$ & Dy1-O25-Dy2 & $108.59(1)$ \\
\hline $\mathrm{Gd}_{2}-\mathrm{O}_{25}-\mathrm{Gd}_{3}$ & $108.70(2)$ & Tb1-O25-Tb3 & 108.64(1) & Dy1-O25-Dy3 & $110.21(1)$ \\
\hline $\mathrm{Gd}_{1}-\mathrm{O}_{25}-\mathrm{Gd}_{3}$ & $108.79(2)$ & $\mathrm{Tb}_{2}-\mathrm{O}_{25}-\mathrm{Tb}_{3}$ & $108.58(1)$ & $\mathrm{Dy}_{2}-\mathrm{O}_{25}-\mathrm{Dy} 3$ & 109.05(1) \\
\hline \multicolumn{2}{|l|}{7} & \multicolumn{2}{|l|}{8} & \multicolumn{2}{|l|}{9} \\
\hline $\mathrm{Ho1}_{2} \mathrm{O}_{25}$ & $2.361(4)$ & Er1-O25 & $2.350(3)$ & Tm1-O25 & $2.311(5)$ \\
\hline $\mathrm{Ho}_{2}-\mathrm{O}_{25}$ & $2.319(4)$ & $\mathrm{Er}_{2}-\mathrm{O}_{25}$ & $2.324(3)$ & $\mathrm{Tm}_{2}-\mathrm{O}_{25}$ & $2.332(5)$ \\
\hline $\mathrm{Ho}_{3}-\mathrm{O}_{25}$ & $2.391(4)$ & $\mathrm{Er}_{3}-\mathrm{O}_{25}$ & $2.369(3)$ & $\mathrm{Tm}_{3}-\mathrm{O}_{25}$ & $2.312(5)$ \\
\hline Ho1-Ho2 & $3.803(8)$ & Er1-Er2 & $3.793(6)$ & Tm1-Tm2 & $3 \cdot 742(7)$ \\
\hline Ho1-Ho3 & $3.896(9)$ & Er1-Er3 & $3.874(7)$ & Tm1-Tm3 & $3.749(6)$ \\
\hline $\mathrm{Ho}_{3}-\mathrm{Ho}_{2}$ & $3.849(8)$ & Er2-Er3 & $3.835(6)$ & $\operatorname{Tm} 2-\operatorname{Tm} 3$ & $3.756(5)$ \\
\hline $\mathrm{Ho1}-\mathrm{O} 25-\mathrm{Ho} 2$ & $108.69(1)$ & Er1-O25-Er2 & $108.49(1)$ & Tm1-O25-Tm2 & $107.4(2)$ \\
\hline $\mathrm{Ho1}_{-} \mathrm{O}_{25}-\mathrm{Ho}_{3}$ & $110.17(1)$ & Er1-O25-Er3 & $110.34(1)$ & $\mathrm{Tm}_{1}-\mathrm{O}_{25}-\mathrm{Tm} 3$ & $108.4(2)$ \\
\hline $\mathrm{H}_{2}-\mathrm{O}_{25}-\mathrm{Ho}_{3}$ & $109.58(1)$ & Er2-O25-Er3 & $109.60(1)$ & $\mathrm{Tm}_{2}-\mathrm{O}_{25}-\mathrm{Tm}_{3}$ & $108.0(2)$ \\
\hline
\end{tabular}




\section{Molecular structures of 6-8}

Single crystal X-ray diffraction studies reveal that the isomorphous compounds 6-8 crystallize in the triclinic space group, $P \overline{1}$. Unlike in compounds $\mathbf{1}-\mathbf{5}$, the asymmetric unit contains an anionic pentanuclear lanthanide organophosphate unit, with six phosphate ligands, one $\mu_{3}-\mathrm{OH}$ group at the core, three chelating nitrate groups along with five coordinated methanol and two water molecules. The presence of a half molecule of a doubly protonated cationic $\left(\text { tmedaH }_{2}\right)^{2+}$ group balances the overall charge of the asymmetric unit. In addition to this, there are five non coordinating methanol and two water molecules in the crystal lattice. A perspective view of the molecular structure of compound $\mathbf{6}$ as a representative example is shown in Figure 7. Compounds 6-8 contain a similar $\mu_{3}-\mathrm{OH}$ centered metal ion trinuclear unit as seen for $\mathbf{1}-\mathbf{5}-\left[\mathrm{Dy}_{3}\left(\mu_{3}-\mathrm{OH}\right)(\operatorname{dipp})_{6}\right]$. The triangular metal ion unit (Dy1-Dy3) is connected to the two peripheral metal ions (Dy4 and Dy5) via the six phosphate ligands. Again the six dipp ${ }^{2-}$ ligands display two unique bridging modes - [3.111] or [3.211], again as seen for 1-5. The average metal oxygen distance in the trinuclear $\left[\mathrm{Dy}_{3}\left(\mu_{3}-\mathrm{OH}\right)\right]$ unit is $2.365 \AA$, whereas the average metal-metal distance is $3.857 \AA$. The bridging $\mu_{3}-\mathrm{OH}$ lies $0.794 \AA$ above the mean plane formed by Dy1, Dy2 and Dy3. The angles around the $\mu_{3}-\mathrm{OH}$ are in the range of 108.64(1) - 110.24(1) ${ }^{\circ}$. The metal-metal distances between the peripheral and the central dysprosium ions vary in the range 5.236-5.605 $\AA$ and the metal-metal distance between the peripheral dysprosium ions is 9.833(1) $\AA$. The three nitrate anions chelate to Dy1, Dy4 and Dy5. This differs from 1, where the nitrates are chelated to the peripheral $\mathrm{Nd}^{\mathrm{III}}$ ions only ( $\mathrm{Nd}_{4}$ and $\left.\mathrm{Nd}_{5}\right)$. The coordination of Dyı is supported solely by chelating nitrate anion and phosphate oxygen atoms unlike in the previous cases (1-5). While the coordination number of the central metal ions remain same, that of the peripheral Dy(III) ions are reduced by one with one solvent molecule less (Table S2o).

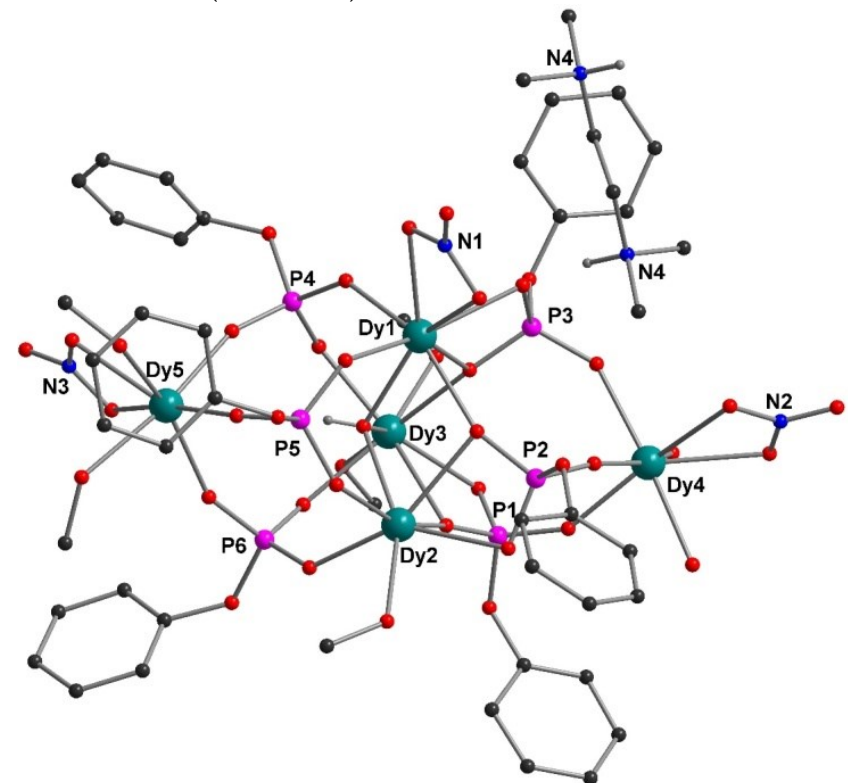

Figure 7. Molecular structure of 6 showing the anionic pentanuclear dysprosium organophosphate cluster with the charge balancing protonated cationic tmeda molecule. The full tmeda molecule of the unit cell is shown. Isopropyl groups, lattice solvates and most hydrogen atoms are removed for clarity. a)

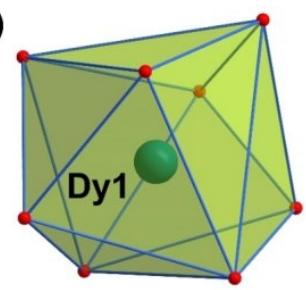

c)

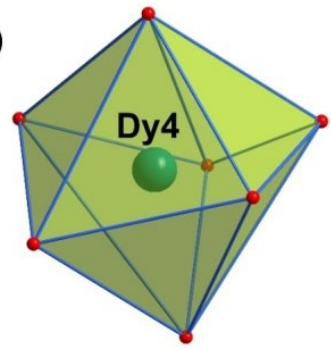

b)

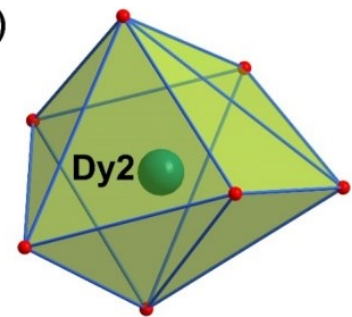

d)

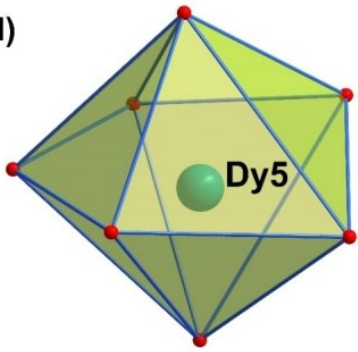

e)

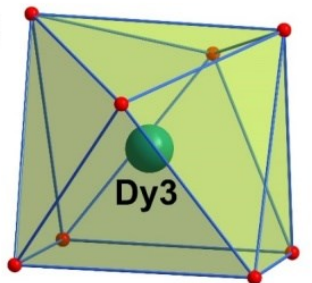

Figure 8 (a-e). Distorted coordination geometry around the five Dy(III) ions with ligating oxygen atoms in 6.

Two Dy(III) ions are eight coordinate and three Dy(III) ions are seven coordinate (Table $\mathrm{S}_{17}$ and $\mathrm{S} 18$ ). This differs from 1 - 5 where four are eight coordinate and one is seven coordinate. The eight coordinate Dyı and Dy3 sites adopt distorted triangular dodecahedron and biaugmented trigonal prismatic geometries, respectively. The seven coordinate Dyz and Dy4 sites display the distorted capped trigonal prismatic environment. Dy5 shows least deviation from the ideal $D_{5 \mathrm{~h}}$ symmetry showing small distortion from the pentagonal bipyramidal geometry (Figure 8 ).

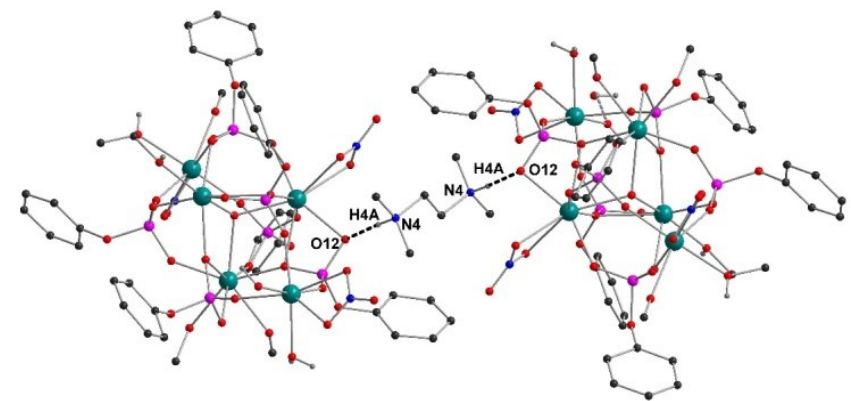

Figure 9. The role of the protonated $\left(\mathrm{tmedaH}_{2}\right)^{2+}$ cation in forming H-bonded dimers in $\mathbf{6}$.

The doubly protonated $\left(\mathrm{tmedaH}_{2}\right)^{2+}$ molecule facilitates strong intermolecular $\mathrm{H}$-bonding forming a dimer of the pentanuclear rare-earth organophosphate complexes (Figure 9). In addition to the $\left(\text { tmedaH }_{2}\right)^{2+}$ moiety, the coordinated and lattice solvent molecules are also involved in extensive intermolecular and intramolecular $\mathrm{H}$-bonding leading to the formation of two-dimensional self-assembled 
hydrogen bonded networks similar to that observed for 1 - 5 (Figure $\mathrm{S}_{5}$ ).

\section{Molecular structure of 9}

Unlike 1-8, compound 9 crystallizes in the monoclinic space group $P 2_{1} / n$. The asymmetric part of the unit cell contains five thulium ions, seven doubly deprotonated phosphates, one bridging $\mu_{3}-\mathrm{OH}$ and coordinated methanol (seven) and water (two) molecules. Contrary to compounds 15, where in addition to the $\mu_{3}-\mathrm{OH}$ and six dipp ${ }^{2-}$ ligands the cationic charge is balanced by two chelating nitrate ions, for 9 the charge is balanced by an extra coordinated dipp ${ }^{2-}$ ligand, instead of the two chelating nitrate anions. In addition, there are five non-coordinating methanol and three water molecules present in the lattice. The molecular structure of $\mathbf{9}$ is depicted in Figure 10, with the same metal ion core observed for $\mathbf{1}-\mathbf{8}$. The average metal-oxygen distance in the trinuclear $\left[\mathrm{Tm}_{3}\left(\mu_{3}-\mathrm{OH}\right)(\operatorname{dipp})_{6}\right]$ unit is $2.315 \AA$, whereas the average metal-metal distance is $3.747 \AA$. The deviation of $\mathrm{O}_{25}$ from the mean plane formed by Tm1, Tm2, and Tm 3 is $0.842 \AA$. Of the seven phosphate ligands present six are bridging and one lies terminal. The six bridging phosphate ligands again bind with the [3.111] or [3.211] modes, whereas the lone terminal phosphate ligand binds in [1.100] mode (Figure 11).31The metalmetal distance between the peripheral and central thulium vary over the range 5.315-5.354 $\AA$ and the distance between the two peripheral thulium atoms (Tm4 and Tm5) is $9.699 \AA$.

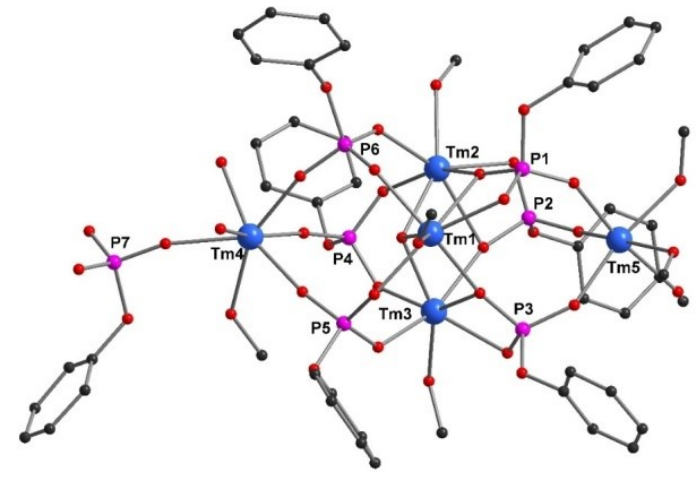

Figure 10. Molecular structure of pentanuclear thulium organophosphate 9. Isopropyl groups, lattice solvates and most hydrogen atoms are removed for clarity.

As we move along the lanthanide series, the coordination number of the thulium ions are further reduced compared to $\mathbf{1}-\mathbf{8}$. Tm1-Tm4 are seven coordinate, while Tm5 is six coordinate (Table S19 and Figure 12). Tmı displays a distorted capped trigonal prismatic environment, Tm2 and
Tm3 adopts a pentagonal bipyramidal geometry and Tm4 shows least deviation for the $C_{3 v}$ symmetry with a distorted capped octahedron environment. Tm 5 adopts an octahedral geometry, showing least deviation form $\mathrm{O}_{\mathrm{h}}$ symmetry.

Complex 9 forms a one-dimensional chain of pentanuclear units, a consequence of the hydrogen bonding between the terminal phosphate and $\mathrm{MeOH} / \mathrm{H}_{2} \mathrm{O}$ groups, in contrast to the two-dimensional sheets formed in the previous examples 1-8 (Figure 13).

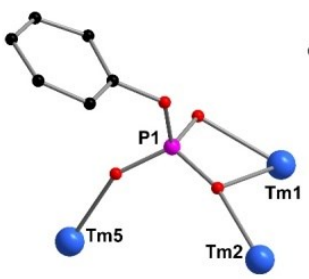

[3.211]

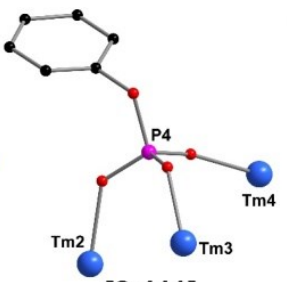

[3.111]

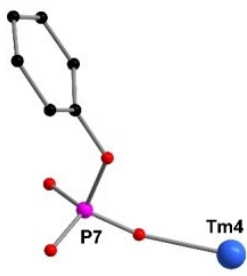

[1.100]
Figure 11. Binding modes of the phosphate ligands in 9. a)

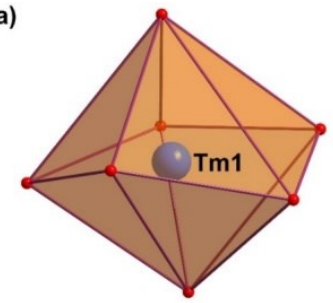

c)

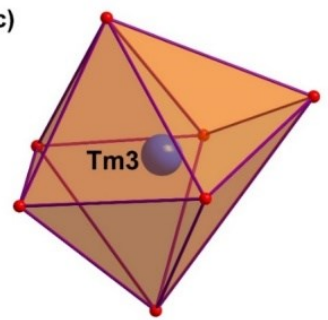

d)
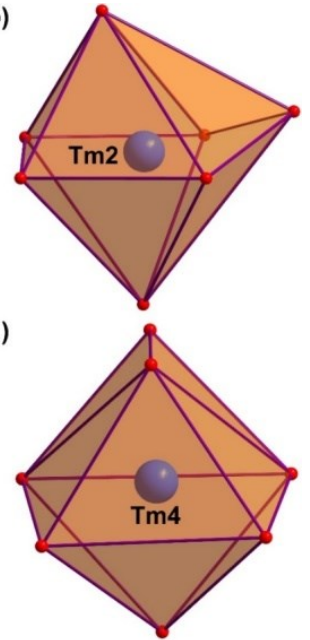

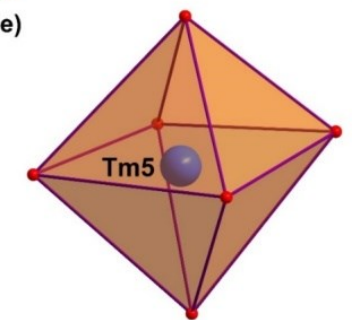

Figure 12 (a-e). Polyhedra showing the coordination environment of the five Tm(III) ions in $\mathbf{9}$.

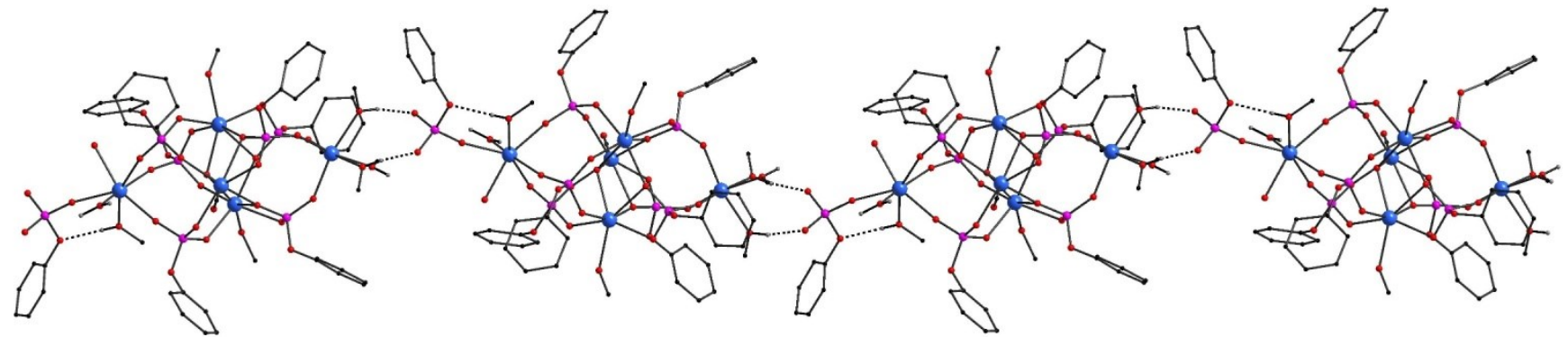

Figure. 13. Intermolecular H-bonding in 9 leading to the formation of linear polymer of pentanuclear rare-earth phosphate clusters. 
Lanthanide Contraction: Analysis of $\mathrm{Ln}-\left(\mu_{3}-\mathrm{OH}\right)$ bond lengths and $\mathrm{Ln}_{4} \cdots \mathrm{Ln}_{5}$ distances

It is a well-known fact that the ionic radius of $\mathrm{Ln}$ (III) ions decrease with increasing atomic number, an effect of weak shielding by f-electrons in the diffused f-orbitals (lanthanide contraction). This effect commonly results in the reduction of the coordination number around the central $\mathrm{Ln}$ (III) ion as we move along the series and can also alter the binding mode of the ligand. This, in turn, results in the alteration of the topological structure of the product that results from the reaction. However, apart from the $\operatorname{Ln}(\mathrm{III})$ ionic radii, the deviation in structural features across the series also depends on the nature and denticity of the coordinating ligands. In the present scenario, the Ln(III) ions in the pentanuclear lanthanide phosphate compounds 1-9, show variable coordination numbers ranging from eight to six, decreasing along the series. This can be correlated to the decrease in ionic radii of the respective lanthanide ions with increasing effective nuclear charge. The structural differences in compounds 1-9, however, impede the evaluation of lanthanide contraction by the quadratic relationship using Slater's model of ionic radii. Although 1-9 are not isomorphous and isostructural due to the varying nature of charge balancing species and coordinating solvent molecules, the average $\mathrm{Ln}-\left(\mu_{3}-\mathrm{OH}\right)$ bond lengths in the central triangle was considered for examining the decrease in Ln-O bond lengths (Table 3). In Figure 14, the dependence of the average Ln$\mathrm{O}_{25}\left(\mu_{3}-\mathrm{OH}\right)$ bond length on electronic configuration reveals a steady decrease in the Ln-O distance with increasing atomic number, as one would expect as a consequence of lanthanide contraction. The average $\mathrm{Ln}-\mathrm{O}_{25}$ distance varies in the range 2.467-2.327 $\AA$. The decrease in the Ln-O25 bond length in turn results in the reduction of Ln $\cdots \operatorname{Ln}$ distances within the trinuclear $\left[\operatorname{Ln}_{3}\left(\mu_{3}-\mathrm{OH}\right)(\text { dipp })_{6}\right]$ unit (Table 3 and Figure 15 ). Additionally, the combined effect of the decrease in Ln-O bond distances in the pentanuclear lanthanide phosphates results in the decrease of the overall distance between the peripheral $\operatorname{Ln}(\mathrm{III})$ ions (Table 3) in the range of 10.266-9.669 $\AA$ as depicted in Figure 14. The sudden drop in the Ln $4 \cdots$ Ln 5 distance after compound $\mathbf{5}$ is due to the change in the core structure where an additional nitrate anion chelates to one of the $\mathrm{Ln}(\mathrm{III})$ ion of the central $\mathrm{Ln}-\mathrm{O}\left(\mu_{3}-\mathrm{OH}\right)$ triangle. Table 3 lists the average $\mathrm{Ln}-\mathrm{O}_{25}$ bond lengths and overall $\mathrm{Ln} \cdots \mathrm{Ln}$ distances in compounds 1-9.

Table 3. Average Ln- $\left(\mu_{3}-\mathrm{OH}\right)$ bond distance and Ln $\cdots$ Ln distances $(\AA)$ within the trinuclear $\left[\operatorname{Ln}_{3}\left(\mu_{3}-\mathrm{OH}\right)(\operatorname{dipp})_{6}\right]$ unit and the distance between the peripheral lanthanide ions $(\AA)$ in the pentanuclear lanthanide organophosphate series.

\begin{tabular}{|c|c|c|c|}
\hline Compound & av. Ln-O25 & av. Ln...Ln & Ln4 ......Ln5 \\
\hline $1\left(\mathrm{Nd}^{\mathrm{III}}\right)$ & 2.464 & 4.017 & 10.266 \\
\hline $2\left(\mathrm{Sm}^{\mathrm{III}}\right)$ & 2.433 & 3.957 & 10.212 \\
\hline $3\left(\mathrm{Eu}^{\mathrm{III}}\right)$ & 2.414 & 3.934 & 10.184 \\
\hline $4\left(\mathrm{Gd}^{\mathrm{III}}\right)$ & 2.407 & 3.915 & 10.149 \\
\hline $5\left(\mathrm{~Tb}^{\mathrm{III}}\right)$ & 2.397 & 3.899 & 10.106 \\
\hline $6\left(\mathrm{Dy}^{\mathrm{III}}\right)$ & 2.364 & 3.857 & 9.834 \\
\hline $7\left(\mathrm{Ho}^{\mathrm{III}}\right)$ & 2.361 & 3.849 & 9.846 \\
\hline $8\left(\mathrm{Er}^{\mathrm{III}}\right)$ & 2.347 & 3.834 & 9.802 \\
\hline $9\left(\mathrm{Tm}^{\mathrm{III}}\right)$ & 2.323 & 3.749 & 9.699 \\
\hline
\end{tabular}

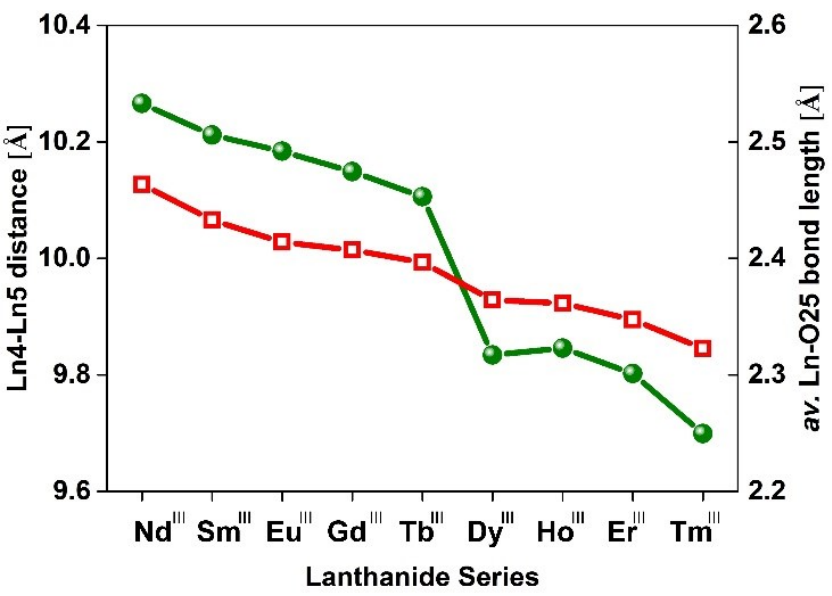

Figure 14. Plot of the distance between the peripheral lanthanide ions $(\AA)$ and the average $\mathrm{Ln}-\mathrm{O}\left(\mu_{3}-\mathrm{OH}\right)$ bond distance for $\mathbf{1}$ - 9, highlighting the effect of lanthanide contraction.

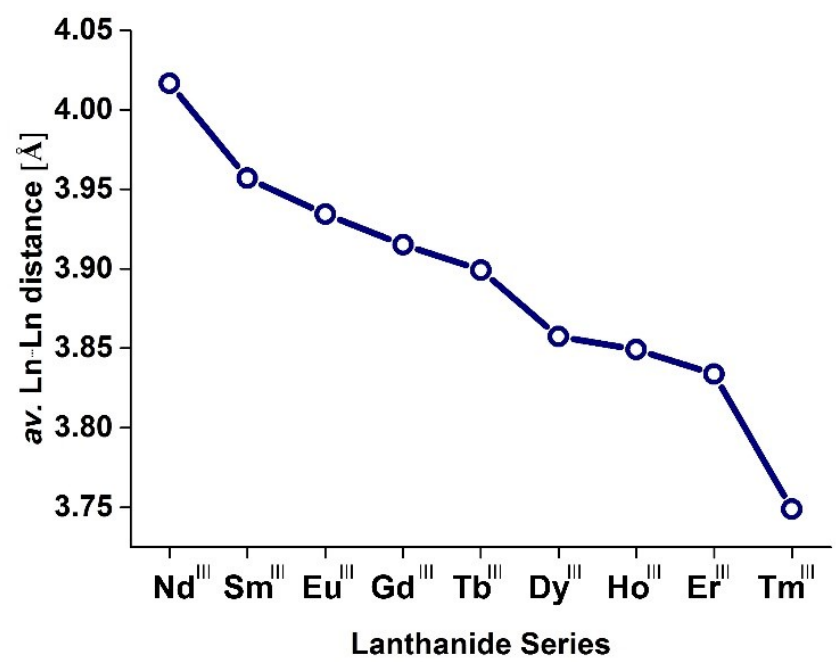

Figure 15. Plot of the average Ln-Ln distance in the central triangular unit for $\mathbf{1}-\mathbf{9}$, highlighting the effect of lanthanide contraction.

\section{Magnetic Properties}

Rare-earth metal complexes have played a major role in the advancement of molecular magnetism in the last few years. The magnetic properties of these rare-earth phosphates have been investigated via dc and ac magnetic susceptibility measurements, between 1.8 to $300 \mathrm{~K}$. The dc magnetic susceptibility data were measured with an applied field of 1.0 $\mathrm{T}$ in the temperature range 2-300 K. Figures 16 and 17 show the temperature dependence of $\chi_{\mathrm{M}} \mathrm{T}\left(\chi_{\mathrm{M}}=\right.$ molar susceptibility) and the field dependence of magnetization of 1-9, respectively. The expected value for non-interacting $\mathrm{Ln}^{\text {III }}$ ions and the magnetization $\left(\mu_{B}\right)$ values at $2 \mathrm{~K}$ are presented in Table 4 . The $\chi_{\mathrm{M}} \mathrm{T}$ values obtained experimentally for all the complexes are in agreement with calculated values for five non-interacting lanthanide ions at $300 \mathrm{~K}$, except for complex $2\left(\mathrm{Sm}^{\mathrm{III}}\right)$ (Table 4). The dc susceptibility of the pentanuclear gadolinium cluster, 4, was reported in the preliminary communication, where the interactions among the $\mathrm{Gd}^{\mathrm{III}}$ ions in the central $\left[\mathrm{Gd}_{3}\left(\mu_{3}-\mathrm{OH}\right)(\mathrm{dipp})_{6}\right]$ unit and the interaction of the central 
Table 4. Summary of the static magnetic susceptibility measurement data in $\mathrm{cm}^{3} \mathrm{~K} \mathrm{~mol}^{-1}$, and effective magnetic moments, in $\mu_{\mathrm{B}}$, at $300 \mathrm{~K}$

\begin{tabular}{|c|c|c|c|c|c|c|c|}
\hline & $4 \mathrm{f}$ ion & ${ }^{2 \mathrm{~S}+1} \mathrm{~L}_{j}$ & $\begin{array}{l}\text { Expected } \mu_{\text {eff }} \\
\text { values }\left(\mu_{\mathrm{B}}\right) \\
\text { for all ions }\end{array}$ & $\begin{array}{l}\text { Expected } \chi_{M} T \\
\text { value for all ions } \\
\left(\mathrm{cm}^{3} \mathrm{~K} \mathrm{~mol}^{-1}\right)\end{array}$ & $\begin{array}{l}\text { Experimental } \mu_{\text {eff }} \\
\text { values }\left(\mu_{\mathrm{B}}\right)\end{array}$ & $\begin{array}{l}\text { Experimental } \chi_{M} T \\
\text { value }\left(\mathrm{cm}^{3} \mathrm{~K} \mathrm{~mol}^{-1}\right)\end{array}$ & $\begin{array}{l}\text { Magnetization } \\
\left(N \mu_{\mathrm{B}}\right) \text { at } 2 \mathrm{~K} \text { and } \\
5.0 \mathrm{~T}\end{array}$ \\
\hline 1 & $\mathrm{Nd}^{\mathrm{III}}$ & $4 I_{9 / 2}$ & 8.10 & 8.20 & 8.21 & 8.41 & 7.66 \\
\hline 2 & $\mathrm{Sm}^{\mathrm{III}}$ & ${ }^{6} \mathrm{H}_{5 / 2}$ & 1.90 & 0.45 & 3.65 & 1.66 & 0.36 \\
\hline 3 & $\mathrm{Eu}^{\mathrm{III}}$ & $7 \mathrm{~F}_{\mathrm{o}}$ & 0 & 0 & $7 \cdot 37$ & 6.80 & 0.28 \\
\hline 4 & $\mathrm{Gd}^{\mathrm{III}}$ & ${ }^{8} S_{7 / 2}$ & 17.76 & 39.40 & 17.80 & 39.58 & 29.62 \\
\hline 5 & $\mathrm{~Tb}^{\mathrm{III}}$ & $7 \mathrm{~F}_{6}$ & 21.75 & 59.05 & 21.75 & 59.06 & 24.72 \\
\hline 6 & Dy III & ${ }^{6} \mathrm{H}_{15 / 2}$ & 23.83 & 70.90 & 23.76 & 70.47 & $27 \cdot 5^{2}$ \\
\hline 7 & $\mathrm{Ho}^{\mathrm{III}}$ & $5 I_{8}$ & 23.74 & 70.35 & 23.68 & 70.03 & $27 \cdot 38$ \\
\hline 8 & $\mathrm{Er}^{\mathrm{III}}$ & $4 I_{15 / 2}$ & 21.44 & 57.40 & 21.48 & 57.64 & 25.98 \\
\hline 9 & $\mathrm{Tm}^{\mathrm{III}}$ & $3 \mathrm{H}_{6}$ & 16.92 & 35.75 & 17.00 & 36.07 & 15.39 \\
\hline
\end{tabular}

GdIII ions with the two peripheral ions, both being antiferromagnetic. ${ }^{8 f}$ The best fit parameters obtained for the pentanuclear gadolinium phosphate cluster were $J_{1}=-0.011$ $\mathrm{cm}^{-1}$ and $J_{2}=-0.001 \mathrm{~cm}^{-1}$ (where $J_{1}$ is the magnetic exchange interaction among the central $\mathrm{Gd}_{3}-\mathrm{O}\left(\mu_{3}-\mathrm{OH}\right)$ unit and $J_{2}$ is the magnetic exchange interaction between the $\mathrm{Gd}{ }^{\mathrm{III}}$ ions of the central triangle with the peripheral Gd ${ }^{\text {III }}$ ions). Due to these weak magnetic exchange interactions between the isotropic ions, 4 reveals a significant entropy change $\left(-\Delta \mathrm{S}_{\mathrm{m}}\right)$ of $25.8 \mathrm{~J}$ $\mathrm{kg}^{-1} \mathrm{~K}^{-1}$, at $\Delta \mathrm{H}=7 \mathrm{~T}^{8 \mathrm{f}}$

The $\chi_{\mathrm{M}} T$ value of $8.41 \mathrm{~cm}^{3} \mathrm{~K} \mathrm{~mol}^{-1}$ at $300 \mathrm{~K}$ for $\mathbf{1}$ is in good agreement with the expected value for five noninteracting $\mathrm{Nd}^{\mathrm{III}}$ ion $(S=3 / 2, L=6, J=9 / 2, g=8 / 11$; ground term symbol $4 \mathrm{I}_{9 / 2}$ ) and remains almost constant to $150 \mathrm{~K}$. Further cooling below $150 \mathrm{~K}$ shows a gradual decrease in $\chi_{\mathrm{M}} T$ value reaching a value of $3.43 \mathrm{~cm}^{3} \mathrm{~K} \mathrm{~mol}^{-1}$ at $2 \mathrm{~K}$. The magnetic behavior of anisotropic lanthanide ions is often very complex and difficult to interpret without advanced analysis (theoretical and experimental). The behavior is an interplay of ligand field and spin-orbit effects, which determines a spectrum of $m_{J}$ states intrinsically active in Boltzmann population dynamics. It is not a trivial task to determine the energy and nature of such states. For polynuclear complexes magnetic exchange interactions must also be considered, further complicating the analysis. The decrease in the $\chi_{\mathrm{M}} T$ value as the temperature is reduced is commonly attributed to depopulation of the $m_{J}$ magnetic states (i.e. thermal depopulation of the $\mathrm{Nd}$ (III) Stark sub levels of the term, $4 \mathrm{I}_{9 / 2}$ ), which is likely the case here, however, the decrease also offers the possibility that antiferromagnetic interactions between the $\mathrm{Nd}(\mathrm{III})$ ions are active (dominant). Unfortunately, given the complexity of the system, the profile of the temperature dependence of the magnetic susceptibility cannot be rationalized by "simple" speculation. We can, however, use the data obtained from our analysis of the isotropic $\left\{\mathrm{Gd}_{5}{ }_{5}\right\}$ system, complex 4, which revealed antiferromagnetic interactions between nearest neighbor ions, as a guide. This therefore, indicates that the decrease in the $\chi_{\mathrm{M}} T$ product is a consequence of single ion thermal depopulation effects and dominant inter-ion antiferromagnetic interactions.

In contrast to 1 , the $\chi_{\mathrm{M}} T$ value $1.66 \mathrm{~cm}^{3} \mathrm{~K} \mathrm{~mol}^{-1}$ at $300 \mathrm{~K}$ for 2 is much higher than that expected for five non-interacting $\mathrm{Sm}^{\mathrm{III}}$ ions $(\mathrm{S}=5 / 2, \mathrm{~L}=5, \mathrm{~J}=5 / 2, g=2 / 7$; ground term symbol ${ }^{6} \mathrm{H}_{5 / 2}$ ), a situation frequently observed in many $\mathrm{Sm}^{\mathrm{III}}$-based complexes due to the presence of low-lying excited multiplets. 33 The $\chi_{M} T$ value shows a linear dependence on temperature reaching a value of $0.09 \mathrm{~cm}^{3} \mathrm{~K} \mathrm{~mol}^{-1}$ at $2 \mathrm{~K}$.

Compounds 5-9 display similar behavior in the temperature dependence of $\chi_{M} T$ values. The experimental $\chi_{M} T$ values are in good agreement with the corresponding values for five noninteracting ions (see Table 4 ). These values gradually decrease, a little, down to $\sim 50 \mathrm{~K}$ before decreasing sharply on further cooling down to $2 \mathrm{~K}$. The arguments provided for the magnetic behavior of 1 holds true for these anisotropic Tb (5), Dy (6), Ho (7), $\operatorname{Er}(8)$ and $\operatorname{Tm}(9)$ ions. We can, again, tentatively conclude from the data that single ion depopulation and antiferromagnetic interactions are responsible for the $\chi_{M} T(\mathrm{~T})$ profiles. The magnetization versus field data plots for compounds 1-9 (Fig 17), at $2 \mathrm{~K}$, reveal no clear saturation up to a field of 5.0 T, except perhaps for 6 (Dy) which suggests the presence of magnetic anisotropy in these compounds (Figure 17).

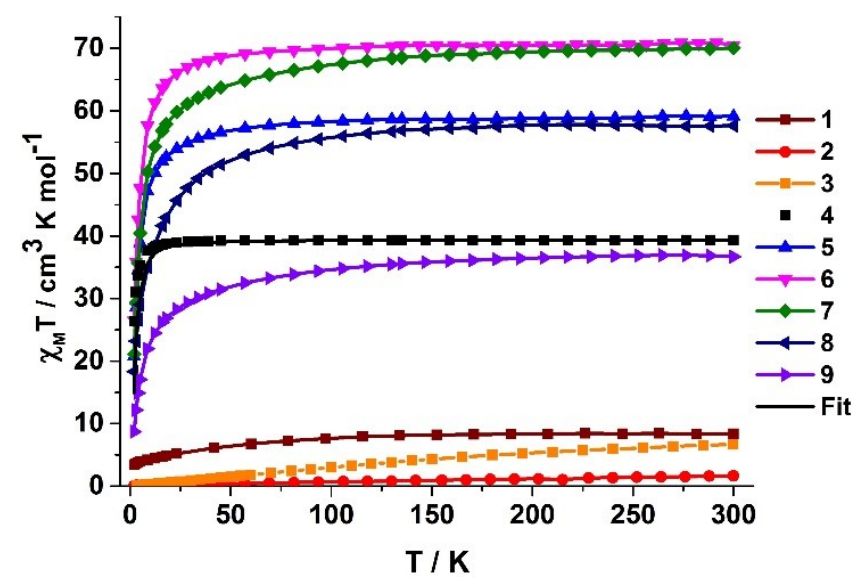

Figure 16. Temperature dependence of the $\chi_{M} T$ product under an applied field of 1.o T. (Symbols - experimental points; the black line is the best fit to $\mathbf{4}$ and coloured lines are guides to the eye). 


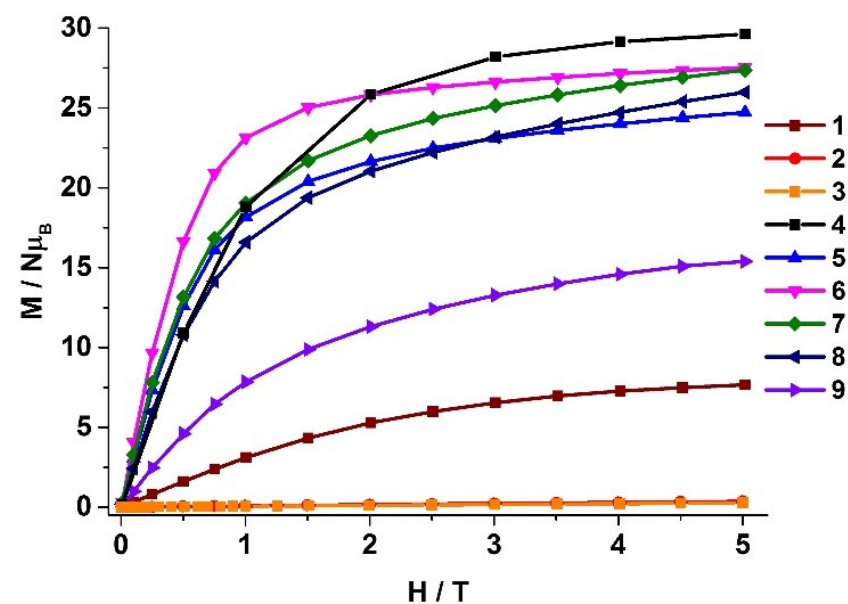

Figure 17. Field dependences of the magnetization at $2 \mathrm{~K}$. Solid lines are guides to the eye.

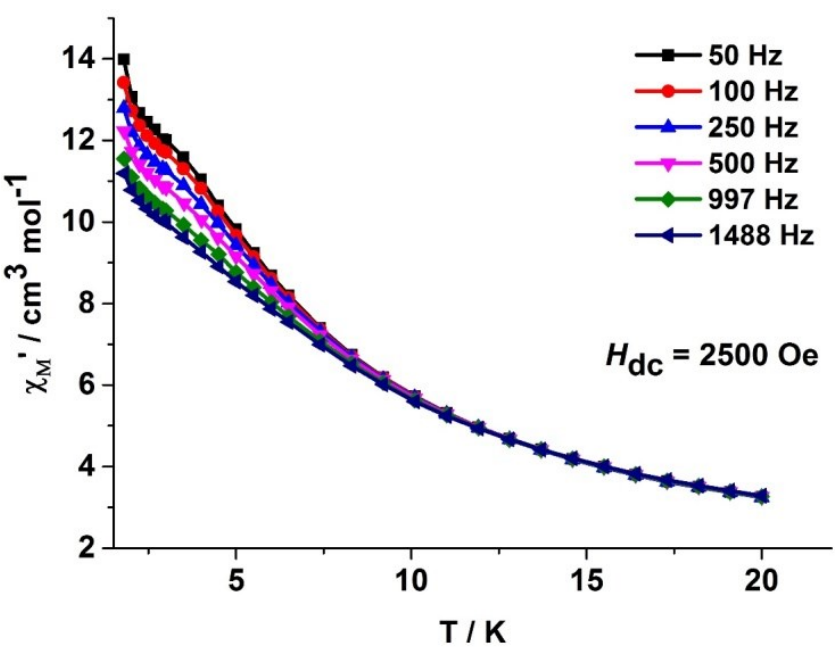

Figure 18. Temperature dependence of the real component of the ac susceptibility $\left(\chi^{\prime}\right)$ for $\mathbf{6}$ under an applied dc field of $\mathbf{2 5 0 0}$ Oe with a 3.5 Oe oscillating ac field.

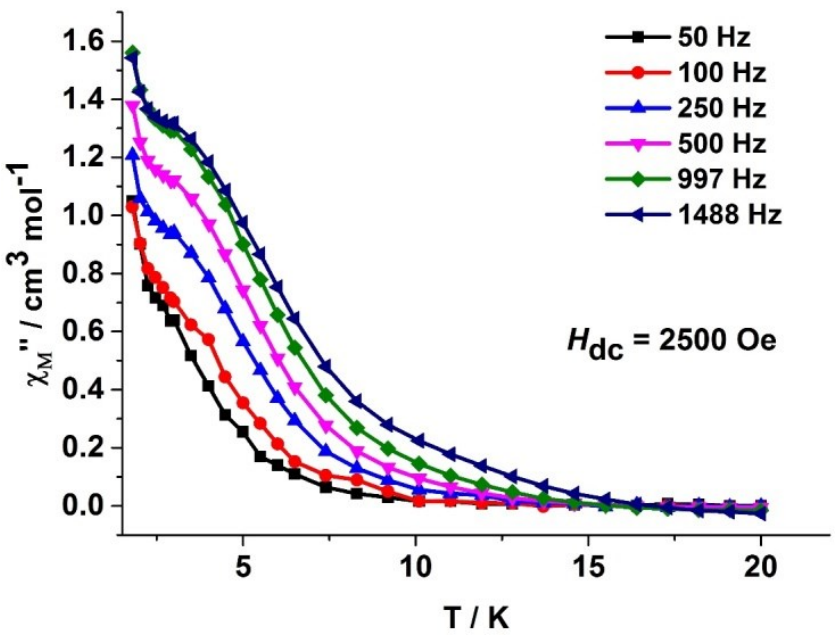

Figure 19. Temperature dependence of the imaginary component of the ac susceptibility $\left(\chi^{\prime \prime}\right)$ for $\mathbf{6}\left(\mathrm{Dy} \mathrm{y}^{\mathrm{III}}\right)$ under an applied dc field of 2500 Oe with a 3.5 Oe oscillating ac field.

In order to probe for the presence of magnetic anisotropy and SMM behaviour, ac magnetic susceptibility measurements were carried out. Compounds 1 - 5 and 7 - 9 revealed an absence of out-of-phase susceptibility signals down to $1.8 \mathrm{~K}$, indicating no slow relaxation of the magnetization is observed above this temperature. Compound 6 (Dy $\left.{ }^{\mathrm{III}}\right)$ on the other hand revealed non-zero outof-phase ac susceptibility signals $\left(\chi^{\prime \prime}\right)$, however no maxima are observed as a function of frequency, (Figure Sio). As a consequence, no relaxation times can be extracted. If magnetic relaxation via quantum tunneling of the magnetization (QTM) is active then this relaxation process is generally very fast for lanthanide based complexes, often much faster than the thermally activated process at very low temperatures. The application of an applied field can slow the relaxation time of this process, therefore, allowing for the observation of the thermally activated mechanism. Upon the application of dc field of 2500 Oe, clear temperature dependent out-of-phase $\left(\chi_{M}{ }^{\prime \prime}\right)$ components of the susceptibility were observed at different frequencies, but the maxima are obscured by a second increase at the lowest temperatures (Figure 19). This behavior clearly indicates the presence of significant QTM, which cannot be quenched even in a 2500 Oe magnetic field. Similar field induced slow magnetic relaxation behavior was observed for 1 and $\mathbf{8}$ (Figure S8 and S12), again indicating QTM is the most efficient magnetic relaxation mechanism.

We note that a number of pentanuclear lanthanide clusters have been reported recently, containing various numbers of hydroxo bridges and various chelating/bridging ligands, and with core $\left\{\mathrm{M}_{5}\right\}$ geometries usually different to that seen here. The magnetic behaviors are similar to those described here and some of the reported $\left\{\mathrm{Dy}_{5}\right\}$ complexes display SMM behavior. 34

Finally we note that the central triangle $\left\{\mathrm{Dy}_{3}\left(\mu_{3}-\mathrm{OH}\right)\right\}$ in $\mathbf{6}$ is reminiscent of that in the archetypical single molecule toroidal (SMT) complex $\left.\left[\mathrm{Dy}_{3}(\mathrm{OH})_{2} \text { (vanillin) }\right)_{3}\right] .35$ There is no evidence of SMT behaviour in $\mathbf{6}$ with the $M$ vs $H$ plot (Figure 17), for example, not showing S-shaped behaviour.

\section{Conclusions}

We have reported the synthesis of a series of pentanuclear lanthanide phosphate complexes derived from the monoester of the phosphoric acid, 2,6diisopropyldihydrogen phosphate and lanthanide nitrate salts. The molecular structures have been determined by single crystal X-ray diffraction analysis and these compounds have been fully characterized both by analytical and spectroscopic techniques. Compounds 1-8 show extensive $\mathrm{H}$-bonding in the solid-state leading to formation of a $2 \mathrm{D}$ sheet of pentanuclear clusters, whereas 9 displays formation of an $\mathrm{H}$-bonded linear polymer. This series of compounds represent the first family of any discrete lanthanide organophosphate complexes using a sterically encumbered phosphate ligand. The effect of the lanthanide contraction was evident from the reduction of the metal ion coordination number and the contraction of metal-ligand bond length as we moved along the series $\mathrm{Nd} \rightarrow \mathrm{Tm}$. Magnetic studies reveal the presence of weak antiferromagnetic magnetic exchange through the bridging $\mu_{3}$-hydroxo and organophosphate ligand for the isotropic $\left\{\mathrm{Gd}_{5}{ }_{5}\right\}$ complex. This $\left\{\mathrm{Gd}_{5} \mathrm{III}_{5}\right\}$ cluster revealed a significant entropy change $\left(-\Delta S_{\mathrm{m}}\right)$ of $25.8 \mathrm{~J} \mathrm{~kg}^{-1} \mathrm{~K}^{-1}$, at $\Delta \mathrm{H}$ 
$=7 \mathrm{~T}$. The anisotropic lanthanide complexes revealed no clear SMM properties above $2 \mathrm{~K}$ due, most likely, to the presence quantum tunneling of magnetization. However, complexes $\mathrm{Nd}$ (1), Dy (6) and $\operatorname{Er}$ (8) show evidence for slow magnetisation relaxation in applied DC fields.

\section{Experimental section}

\section{Instruments, methods and materials}

All the compounds prepared in this study and the starting materials used are air and moisture stable. Hence all the operations were carried out under aerobic conditions. Solvents were distilled prior to use. ${ }^{36}$ Fourier transform infrared spectra were obtained on a Perkin Elmer Spectrum One FT-IR spectrometer as $\mathrm{KBr}$ diluted discs. Microanalyses were performed on a ThermoFinnigan (FLASH EA 1112) microanalyzer. Thermogravimetric analysis was carried out on a Perkin Elmer Pyris Diamond TG/DTA analysis system under a stream of nitrogen gas at a heating rate of $10{ }^{\circ} \mathrm{C} / \mathrm{min}$. The metal content in the samples were measured by inductively coupled plasma atomic emission spectroscopy (ICP-AES). The samples were digested in nitric acid and diluted with distilled water. The magnetic measurements were carried out on a Quantum Design MPMS-XL SQUID magnetometer equipped with a $7 \mathrm{~T}$ magnet. The molar susceptibilities have been calculated using the formulae listed in Table 1 . Alternating current (ac) susceptibility measurements were carried out in an oscillating ac field of 3.5 Oe and frequencies ranging from 0.1 to $1500 \mathrm{~Hz}$.

$\mathrm{Eu}\left(\mathrm{NO}_{3}\right)_{3} \cdot 5 \mathrm{H}_{2} \mathrm{O}, \quad \mathrm{Tb}\left(\mathrm{NO}_{3}\right)_{3} \cdot \mathrm{xH}_{2} \mathrm{O}, \quad \mathrm{Ho}\left(\mathrm{NO}_{3}\right)_{3} \cdot 6 \mathrm{H}_{2} \mathrm{O}$, $\mathrm{Er}\left(\mathrm{NO}_{3}\right)_{3} \cdot{ }_{5} \mathrm{H}_{2} \mathrm{O}, \mathrm{Tm}\left(\mathrm{NO}_{3}\right)_{3} \cdot{ }_{5} \mathrm{H}_{2} \mathrm{O}$ were procured from Sigma Aldrich. TMEDA was purchased from Spectrochem. Hydrated nitrate salts of neodymium, samarium and dysprosium were prepared by dissolving the corresponding oxides in $50 \%$ aqueous nitric acid and evaporating the solution on a steam bath. 2,6-Di-isopropylphenyl phosphate was synthesized as described previously in the literature. 37

\section{X-ray crystallography}

Block shaped crystals obtained in the reaction were found to slowly lose transparency when kept outside mother liquor at ambient conditions. Suitable single crystals of each compound were selected and mounted on a Rigaku Saturn 724+ CCD diffractometer, using Paratone oil for unit cell determination and intensity data collection. Data integration and indexing were carried out using Rigaku suite of programs CrystalClear and CrystalStructure. $3^{8}$ The structures were solved using direct methods (SIR-97).39 Structure refinement and geometrical calculations were carried out using programs in the WinGX module. ${ }^{\circ}$ The final structure refinement was carried out using full least squares methods on $F^{2}$ using SHELXL-2014. ${ }^{41}$ The structure refinement details are summarized in Table 5 and 6 . Some H-atoms in the solvent molecules could not be refined but their contribution has been included in the molecular formula. Disordered atoms or groups have been handled using PART instructions. In case of $\mathbf{5}$, high density peaks around the disordered methanol molecule near Tb5 could not be modeled and hence left untreated. The diffuse electron density in solvent-accessible regions in $\mathbf{9}$ was found to be highly disordered and could not be modeled. SQUEEZE procedure of the PLATON program ${ }^{42}$ was employed that suggests 273 electrons per unit cell occupying a volume of $1180 \mathrm{~A}^{\circ} 3$. This corresponds approximately to two methanol and three water solvates per molecule.

General procedure for synthesis of compounds 1-9. To a solution of $\mathrm{Ln}\left(\mathrm{NO}_{3}\right)_{3} \cdot \mathrm{xH}_{2} \mathrm{O}(0.1 \mathrm{mmol})$ in methanol (10 $\mathrm{mL})$, a solution of $\operatorname{dippH}_{2}(26 \mathrm{mg}, 0.1 \mathrm{mmol})$ in methanol (10 $\mathrm{mL}$ ) was added. The solution was stirred well and tmeda (23.2 $\mathrm{mg}$, $0.2 \mathrm{mmol}$ ) was added to it. The reaction mixture was heated at $60{ }^{\circ} \mathrm{C}$ for $2-3 \mathrm{~h}$ and then cooled to room temperature. Any solid insoluble portion formed was discarded. The solution was then filtered and the clear filtrate was kept for crystallization at room temperature. The solution was filtered repeatedly until no further precipitation was observed during crystallisation. Crystals from the clear mother liquor was obtained within a period of two-three weeks.

Characterization of 1. Yield: $34 \mathrm{mg}(72 \%$, based on dippH $\mathrm{H}_{2}$ ). M.p: $>250^{\circ} \mathrm{C}$. Anal. Calcd. (Found) for $\mathrm{C}_{83} \mathrm{H}_{157} \mathrm{~N}_{2} \mathrm{Nd}_{5} \mathrm{O}_{47} \mathrm{P}_{6}$ : C, 35.07 (35.36); H, 5.57 (5.73); N, 0.99 (1.27); Nd, 25.38 (25.57). FT-IR (KBr, cm-1): 3574 (s), 3429 (m), 2967 (vs), 2870 (s), 1621 (m), 1467 (s), 1442 (s), 1384 (vs), 1362 (m), 1335 (s), 1256 (s), 1177 (vs), 1143 (vs), 1047 (vs), 1003 (s), 913 (vs), 882 (s), 800 (m), 771 (vs), 748 (s), 662 (s), 599 (s), 544 (s), 520 (s). TGA: Temp. range ${ }^{\circ} \mathrm{C}(\%$ Weight loss): 30-111 (5.4); 111-190 (3.9); 190-281 (10.1); 281801 (29.3).

Characterization of 2 . Yield: $36.5 \mathrm{mg}(76 \%$, based on $\operatorname{dippH}_{2}$ ). M.p: $>250^{\circ} \mathrm{C}$. Anal. Calcd. (Found) for $\mathrm{C}_{84} \mathrm{H}_{159} \mathrm{~N}_{2} \mathrm{O}_{47} \mathrm{P}_{6} \mathrm{Sm}_{5}$ : C,34.95 (34.59); H, 5.55 (5.23); N, o.97 (1.19); Sm, 26.04 (26.18). FT-IR ( $\left.\mathrm{KBr}, \mathrm{cm}^{-1}\right): 3577$ (s), 3435 (m), 2966 (vs), 2931 (s), 2870 (s), 1621 (s), 1467 (vs), 1441 (vs), 1384 (vs), 1362 (m), 1335 (s), 1256 (s), 1147 (vs), 1047 (s), 1005 (vs), 914 (vs), 882 (s), 800 (m), 770 (vs), 748 (s), $663(\mathrm{~m}), 600(\mathrm{~m}), 545(\mathrm{~s}), 520(\mathrm{~s})$. TGA: Temp. range ${ }^{\circ} \mathrm{C}$ (\% Weight loss): 30-114 (5.3); 114-188 (4.2); 188-272 (9.3); 272-800 (30.0); 800-1000 (2.5).

Characterization of 3. Yield: $30 \mathrm{mg}(62 \%$, based on $\operatorname{dippH}_{2}$ ). M.p: $>250^{\circ} \mathrm{C}$. Anal. Calcd. (Found) for $\mathrm{C}_{84} \mathrm{H}_{159} \mathrm{Eu}_{5} \mathrm{~N}_{2} \mathrm{O}_{47} \mathrm{P}_{6}$ : C,34.85 (34.72); H, 5.54 (5.68); N, 0.97 (1.07); Eu, 26.25 (26.52). FT-IR (KBr, cm-1): 3589 (s), 3423 (m), 2966 (s), $2869(\mathrm{~m}), 1623(\mathrm{~m}), 1466$ (s), 1440 (s), 1383 (w), 1362 (m), 1336 (s), 1257 (s), 1153 (vs), 1116 (vs), 1047 (s), 1003 (vs), 912 (vs), 880 (m), 770 (vs), 748 (m), 663 (m), 621 $(\mathrm{m}), 598(\mathrm{~m}), 545(\mathrm{~s}), 520(\mathrm{~s})$. TGA: Temp. range ${ }^{\circ} \mathrm{C}(\%$ Weight loss): 30-150 (7.5); 150-265 (11.2); 265-408 (27.7); 408-80o (3.3).

Characterization of 5. Yield: $27 \mathrm{mg}$ (56\%, based on $\operatorname{dippH}_{2}$ ). M.p: $>250^{\circ} \mathrm{C}$. Anal. Calcd. (Found) for $\mathrm{C}_{83} \mathrm{H}_{157} \mathrm{~N}_{2} \mathrm{O}_{47} \mathrm{P}_{6} \mathrm{~Tb}_{5}$ : C, 34.19 (33.8o); H, 5.43 (5.66); N, 0.96 (1.23); Tb, 27.25 (27.65). FT-IR ( $\left.\mathrm{KBr}, \mathrm{cm}^{-1}\right): 3564$ (s), 3418 (s), 3067 (w), 2966 (vs), 2931 (s), 2869 (s), 1622 (m), 1467 (s), 1441 (vs), 1384 (vs), 1362 (m), 1335 (s), 1310 (m), 1256 (s), 
1187 (vs), 1155 (vs), 1046 (vs), 1014 (vs), 918 (vs), 882 (s), 800 (m), 768 (vs), 750 (s), 664 (s), 613 (s), 601 (s), 546 (s), 526 (s). TGA: Temp. range ${ }^{\circ} \mathrm{C}$ (\% Weight loss): 30-132 (4.2); 132-200 (4.8); 200-274 (7.8); 274-800 (30.2).

Characterization of 6 . Yield: $41 \mathrm{mg}(82 \%$, based on $\operatorname{dippH}_{2}$ ). M.p: $>250^{\circ} \mathrm{C}$. Anal. Calcd. (Found) for $\mathrm{C}_{85} \mathrm{H}_{160} \mathrm{Dy}_{5} \mathrm{~N}_{4} \mathrm{O}_{48} \mathrm{P}_{6}$ : C,33.98 (34.36); H, 5.37 (5.63); N, 1.86 (2.27), Dy, 27.04 (27.26). FT-IR (KBr, $\left.\mathrm{cm}^{-1}\right): 3558$ (s), 3418 (m), $3064(\mathrm{~m}), 2966$ (vs), 2870 (s), 2626 (m), 2457 (m), $1618(\mathrm{~m}), 1465$ (s), 1440 (s), 1384 (s), 1335 (s), 1256 (m), 1155 (vs), 1047 (m), 1013 (vs), $916(\mathrm{~s}), 882(\mathrm{~m}), 800(\mathrm{~m}), 770(\mathrm{~s})$, 749 (s), 663 (m), 600 (s), 546 (s), 523 (s). TGA: Temp. range ${ }^{\circ} \mathrm{C}$ (\% Weight loss): 30-102 (2.3); $102-200$ (4.4); 200$269(7.4) ; 269-800(32.2)$.

Characterization of 7 . Yield: $29 \mathrm{mg}$ ( $58 \%$, based on $\operatorname{dippH}_{2}$ ). M.p: $>250^{\circ} \mathrm{C}$. Anal. Calcd. (Found) for $\mathrm{C}_{85} \mathrm{H}_{160} \mathrm{Ho}_{5} \mathrm{~N}_{4} \mathrm{O}_{48} \mathrm{P}_{6}$ : C,33.84 (34.02); H, 5.35 (5.11); N, 1.86 (2.21), Ho, 27.34 (27.46). FT-IR ( $\left.\mathrm{KBr}, \mathrm{cm}^{-1}\right): 3564$ (s), 3434 (m), 2966 (vs), 2931 (s), 2870 (s), 1621 (s), 1467 (vs), 1440 (vs), 1384 (vs), 1362 (s), 1335 (vs), 1256 (s), 1155 (vs), 1047 (vs), 1015 (vs), 917 (vs), 882 (s), 800 (s), 770 (vs), 750 (s), 664 (s), 601 (s), 546 (s), 523 (s), 476 (m). TGA: Temp. range ${ }^{\circ} \mathrm{C}$ (\% Weight loss): 30-100 (2.4); 100-199 (4.1); 199$277(8.4) ; 277-800(30.3)$.

Characterization of $\boldsymbol{8}$. Yield: $42 \mathrm{mg}(84 \%$, based on $\operatorname{dippH}_{2}$ ). M.p: $>250^{\circ} \mathrm{C}$. Anal. Calcd. (Found) for $\mathrm{C}_{85} \mathrm{H}_{160} \mathrm{Er}_{5} \mathrm{~N}_{4} \mathrm{O}_{48} \mathrm{P}_{6}$ : C,33.71 (33.80); H, 5.33 (5.39); N, 1.85 (1.47); Er, 27.62 (27.91). FT-IR ( $\left.\mathrm{KBr}, \mathrm{cm}^{-1}\right)$ : 3546 (s), 3401 (m), 2966 (vs), 2870 (vs), 1615 (m), 1468 (s), 1440 (s), 1384 (s), 1335 (s), 1256 (s), 1155 (vs), 1047 (vs), 1015 (vs), 919 (vs), 882 (s), 800 (s), 770 (vs), 750 (s), 664 (s), 630 (s), 601 (s), 547 (s), 523 (s). TGA: Temp. range ${ }^{\circ} \mathrm{C}$ (\% Weight loss): 30100 (2.4); 100-200 (4.7); 200-274 (8.0); 274-800 (31.4).

Characterization of 9. Yield: $16 \mathrm{mg}\left(36 \%\right.$, based on $\left.\operatorname{dippH}_{2}\right)$. M.p: $>250^{\circ} \mathrm{C}$. Anal. Calcd. (Found) for $\mathrm{C}_{96} \mathrm{H}_{178} \mathrm{O}_{46} \mathrm{P}_{7} \mathrm{Tm}_{5}$ : C,36.84 (37.21); H, 5.73 (5.82); Tm, 26.99 (27.26). FT-IR (KBr, $\left.\mathrm{cm}^{-1}\right)$ : $3584(\mathrm{~s}), 3393(\mathrm{~m}), 3067(\mathrm{~m}), 2967(\mathrm{vs}), 2870(\mathrm{~s}), 1621(\mathrm{~m})$, 1466 (s), 1440 (s), 1384 (s), 1362 (m), 1336 (s), 1256 (s), 1158 (vs), 1128 (vs), 1047 (s), 1013 (vs), 921 (vs), 799 (m), 800 (m), 770 (vs), $752(\mathrm{~m}), 662(\mathrm{~m}), 633(\mathrm{~s}), 601(\mathrm{~s}), 547(\mathrm{~s}), 522(\mathrm{~s}), 481(\mathrm{~m})$. TGA: Temp. range ${ }^{\circ} \mathrm{C}$ (\% Weight loss): 30-78 (2.9); 78-187 (3.0); 187251 (9.0); 251-80o (32.8).

\section{Supporting Information}

†Electronic Supplementary Information (SI) available: Synthesis, crystallographic details, additional figures, and spectral characterization. Crystallographic data of 1-3[CCDC 1520605-152607] and 5-9 [CCDC 1520608-1520612]. This material is available free of charge via the Internet at http://pubs.acs.org.

\section{AUTHOR INFORMATION}

\section{Corresponding Author}

E-mail: rmv@chem.iitb.ac.in

\section{Notes}

The authors declare no competing financial interest.

\section{ACKNOWLEDGMENT}

This work was supported by (1) DST Nanomission (SR/NM/NS-1119/2011), (2) SERB, New Delhi (SB/S1/IC48/2013) and (3) IIT-Bombay Bridge Funding. R. M. thanks SERB (SB/S2/JCB-85/2014), for a J. C. Bose Fellowship. S. K. G. thanks UGC for a research fellowship. The authors thank Dr. S. Kuppuswamy, Prof. G. Rajaraman and T. Rajeshkumar for some of the results reported in the preliminary communication of this work. K. S. M. acknowledges receipt of an Australia-India AISRF grant (with G. Rajaraman).

\section{REFERENCES}

1. (a) Roy, S.; Chakraborty, A.; Maji, T. K. Lanthanide-organic frameworks for gas storage and as magneto-luminescent materials. Coord. Chem. Rev. 2014, 273-274, 139-164. (b) Shi, F.-N.; Almeida Paz, F. A.; Ribeiro-Claro, P.; Rocha, J. Transposition of chirality from diphosphonate metal-organic framework precursors onto porous lanthanide pyrophosphates. Chem. Commun. 2013, 49, 11668-1167o. (c) Ma, S.; Wang, X.-S.; Yuan, D.; Zhou, H.-C. A Coordinatively Linked Yb Metal-Organic Framework Demonstrates High Thermal Stability and Uncommon Gas-Adsorption Selectivity. Angew. Chem. Int. Ed. 2008, 47, 4130-4133. (d) Pan, L.; Adams, K. M.; Hernandez, H. E.; Wang, X.; Zheng, C.; Hattori, Y.; Kaneko, K. Porous Lanthanide-Organic Frameworks: Synthesis, Characterization, and Unprecedented Gas Adsorption Properties. J. Am. Chem. Soc. 2003, 125, 3062-3067.

2. (a) Edelmann, F. T. Lanthanide amidinates and guanidinates in catalysis and materials science: a continuing success story. Chem. Soc. Rev. 2012, 41, 7657-7672. (b) Shibasaki, M.; Yoshikawa, N. Lanthanide Complexes in Multifunctional Asymmetric Catalysis. Chem. Rev. 2002, 102, 2187-2210. (c) Weiss, C. J.; Marks, T. J. Organo-f-element catalysts for efficient and highly selective hydroalkoxylation and hydrothiolation. Dalton Trans. 2010, 39, 6576-6588. (d) Trambitas, A. G.; Panda, T. K.; Jenter, J.; Roesky, P. W.; Daniliuc, C.; Hrib, C. G.; Jones, P. G.; Tamm, M. Rare-Earth Metal Alkyl, Amido, and Cyclopentadienyl Complexes Supported by Imidazolin-2-iminato Ligands: Synthesis, Structural Characterization, and Catalytic Application. Inorg. Chem. 2010, 49, 2435-2446. (e) Fadlallah, S.; Terrier, M.; Jones, C.; Roussel, P.; Bonnet, F.; Visseaux, M. Mixed Allyl-Borohydride Lanthanide Complexes: Synthesis of $\mathrm{Ln}\left(\mathrm{BH}_{4}\right)_{2}\left(\mathrm{C}_{3} \mathrm{H}_{5}\right)(\mathrm{THF})_{3} \quad(\mathrm{Ln}=\mathrm{Nd}, \mathrm{Sm})$, Characterization, and Reactivity toward Polymerization. Organometallics 2016, 35, 456-461. (f) Arnold, P. L.; McMullon, M. W.; Rieb, J.; Kühn, F. E. C-H Bond Activation by f-Block Complexes. Angew. Chem. Int. Ed. 2015, 54, 82100.

3. (a) Carr, R.; Evans, N. H.; Parker, D. Lanthanide complexes as chiral probes exploiting circularly polarized luminescence. Chem. Soc. Rev. 2012, 41, 7673-7686. (b) Armelao, L.; Quici, S.; Barigelletti, F.; Accorsi, G.; Bottaro, G.; Cavazzini, M.; Tondello, E. Design of luminescent lanthanide complexes: From molecules to highly efficient photo-emitting materials. Coord. Chem. Rev. 2o10, 254, 487505. (c) Galyametdinov, Y. G.; Knyazev, A. A.; Dzhabarov, V. I.; Cardinaels, T.; Driesen, K.; Görller-Walrand, C.; Binnemans, K. Polarized Luminescence from Aligned Samples of Nematogenic Lanthanide Complexes. Adv. Mater. 2oo8, 20, 252-257. (d) Zhang, H.; Shan, X.; Zhou, L.; Lin, P.; Li, R.; Ma, E.; Guo, X.; Du, S. Full-colour fluorescent materials based on mixed-lanthanide(iii) metal-organic complexes with high-efficiency white light emission. J. Mater. Chem. C 2013, 1, 888-891. (e) Picot, A.; D'Aléo, A.; Baldeck, P. L.; Grichine, A.; Duperray, A.; Andraud, C.; Maury, O. Long-Lived Two-Photon Excited Luminescence of Water-Soluble Europium Complex: Applications in 
Biological Imaging Using Two-Photon Scanning Microscopy. J. Am. Chem. Soc. 2008, 130, 1532-1533.

4. (a) New, E. J.; Congreve, A.; Parker, D. Definition of the uptake mechanism and sub-cellular localisation profile of emissive lanthanide complexes as cellular optical probes. Chem. Sci. 2010, 1, 111118. (b) Chalmers, K. H.; Kenwright, A. M.; Parker, D.; Blamire, A. M. ${ }_{19} \mathrm{~F}$-lanthanide complexes with increased sensitivity for ${ }_{19} \mathrm{~F}-\mathrm{MRI}$ : Optimization of the MR acquisition. Magn. Reson. Med. 2011, 66, 931936. (c) Hermann, P.; Kotek, J.; Kubicek, V.; Lukes, I. Gadolinium(iii) complexes as MRI contrast agents: ligand design and properties of the complexes. Dalton Trans. 2008, 3027-3047.

5. (a) Peng, H.; Stich, M. I. J.; Yu, J.; Sun, L.-n.; Fischer, L. H.; Wolfbeis, O. S. Luminescent Europium(III) Nanoparticles for Sensing and Imaging of Temperature in the Physiological Range. Adv. Mater. 2010, 22, 716-719. (b) Shinoda, S.; Tsukube, H. Luminescent lanthanide complexes as analytical tools in anion sensing, $\mathrm{pH}$ indication and protein recognition. Analyst 2011, 136, 431-435. (c) Cui, Y.; Xu, H.; Yue, Y.; Guo, Z.; Yu, J.; Chen, Z.; Gao, J.; Yang, Y.; Qian, G.; Chen, B. A Luminescent Mixed-Lanthanide Metal-Organic Framework Thermometer. J. Am. Chem. Soc. 2012, 134, 3979-3982.

6. (a) Layfield, R. A. Organometallic Single-Molecule Magnets. Organometallics 2014, 33, 1084-1099. (b) Woodruff, D. N.; Winpenny, R. E. P.; Layfield, R. A. Lanthanide Single-Molecule Magnets. Chem. Rev. 2013, 113, 5110-5148. (c) Rinehart, J. D.; Fang, M.; Evans, W. J.; Long, J. R. A N23- Radical-Bridged Terbium Complex Exhibiting Magnetic Hysteresis at 14 K. J. Am. Chem. Soc. 2011, 133, 14236-14239. (d) Gregson, M.; Chilton, N. F.; Ariciu, A.-M.; Tuna, F.; Crowe, I. F.; Lewis, W.; Blake, A. J.; Collison, D.; McInnes, E. J. L.; Winpenny, R. E. P.; Liddle, S. T. A monometallic lanthanide bis(methanediide) single molecule magnet with a large energy barrier and complex spin relaxation behaviour. Chem. Sci. 2016, 7, 155-165. (e) Boulon, M.-E.; Cucinotta, G.; Luzon, J.; Degl'Innocenti, C.; Perfetti, M.; Bernot, K.; Calvez, G.; Caneschi, A.; Sessoli, R. Magnetic Anisotropy and SpinParity Effect Along the Series of Lanthanide Complexes with DOTA. Angew. Chem. Int. Ed. 2013, 52, 350-354. (f) Le Roy, J. J.; Ungur, L.; Korobkov, I.; Chibotaru, L. F.; Murugesu, M. Coupling Strategies to Enhance Single-Molecule Magnet Properties of ErbiumCyclooctatetraenyl Complexes. J. Am. Chem. Soc. 2014, 136, 8003-8010. 7. (a) Gupta, S. K.; Rajeshkumar, T.; Rajaraman, G.; Murugavel, R. An unprecedented zero field neodymium(iii) single-ion magnet based on a phosphonic diamide. Chem. Commun. 2016, 52, 7168-7171. (b) Gupta, S. K.; Rajeshkumar, T.; Rajaraman, G.; Murugavel, R. An airstable Dy(iii) single-ion magnet with high anisotropy barrier and blocking temperature. Chem. Sci. 2016, 7, 5181-5191. (c) Blagg, R. J.; Ungur, L.; Tuna, F.; Speak, J.; Comar, P.; Collison, D.; Wernsdorfer, W.; McInnes, E. J. L.; Chibotaru, L. F.; Winpenny, R. E. P. Magnetic relaxation pathways in lanthanide single-molecule magnets. Nat Chem 2013, 5, 673-678. (d) Pugh, T.; Chilton, N. F.; Layfield, R. A. A Low-Symmetry Dysprosium Metallocene Single-Molecule Magnet with a High Anisotropy Barrier. Angew. Chem. Int. Ed. 2016, 55, 1108211085. (e) Pugh, T.; Vieru, V.; Chibotaru, L. F.; Layfield, R. A. Magnetostructural correlations in arsenic- and selenium-ligated dysprosium single-molecule magnets. Chem. Sci. 2016, 7, 2128-2137. (f) Pugh, T.; Tuna, F.; Ungur, L.; Collison, D.; McInnes, E. J. L.; Chibotaru, L. F.; Layfield, R. A. Influencing the properties of dysprosium singlemolecule magnets with phosphorus donor ligands. Nat Commun 2015, 6, 7492.

8. (a) Zheng, Y.-Z.; Zhou, G.-J.; Zheng, Z.; Winpenny, R. E. P. Molecule-based magnetic coolers. Chem. Soc. Rev. 2014, 43, 1462-1475. (b) Zheng, Y.-Z.; Evangelisti, M.; Winpenny, R. E. P. Co-Gd phosphonate complexes as magnetic refrigerants. Chem. Sci. 2011, 2, 99-102. (c) Lorusso, G.; Sharples, J. W.; Palacios, E.; Roubeau, O.; Brechin, E. K.; Sessoli, R.; Rossin, A.; Tuna, F.; McInnes, E. J. L.; Collison, D.; Evangelisti, M. A Dense Metal-Organic Framework for Enhanced Magnetic Refrigeration. Adv. Mater. 2013, 25, 4653-4656. (d) Evangelisti, M.; Brechin, E. K. Recipes for enhanced molecular cooling. Dalton Trans. 201o, 39, 4672-4676. (e) Hooper, T. N.; Schnack, J.; Piligkos, S.; Evangelisti, M.; Brechin, E. K. The Importance of Being Exchanged: $\left[\mathrm{Gd}^{\mathrm{III}}{ }_{4} \mathrm{M}^{\mathrm{II}} 8(\mathrm{OH})_{8}(\mathrm{~L})_{8}\left(\mathrm{O}_{2} \mathrm{CR}\right)_{8}\right]^{4+}$ Clusters for Magnetic Refrigeration. Angew. Chem. Int. Ed. 2012, 51, 4633-4636. (f) Gupta, S. K.; Dar, A. A.; Rajeshkumar, T.; Kuppuswamy, S.; Langley, S. K.; Murray, K. S.; Rajaraman, G.; Murugavel, R. Discrete $\left\{\mathrm{Gd}^{\mathrm{III}}{ }_{4} \mathrm{M}\right\}(\mathrm{M}$ $=\mathrm{Gd}^{\mathrm{III}}$ or $\left.\mathrm{Co}^{\mathrm{II}}\right)$ pentanuclear complexes: a new class of metalorganophosphate molecular coolers. Dalton Trans. 2015, 44, 59615965. (g) Biswas, S.; Mondal, A. K.; Konar, S. Densely Packed Lanthanide Cubane Based 3D Metal-Organic Frameworks for Efficient Magnetic Refrigeration and Slow Magnetic Relaxation. Inorg. Chem. 2016, 55, 2085-209o. (h) Biswas, S.; Adhikary, A.; Goswami, S.; Konar, S. Observation of a large magnetocaloric effect in a $2 \mathrm{D} \mathrm{Gd}$ (iii)based coordination polymer. Dalton Trans. 2013, 42, 13331-13334.

9. (a) Dorman, J. A.; Choi, J. H.; Kuzmanich, G.; Chang, J. P. HighQuality White Light Using Core-Shell $\mathrm{RE}^{3+}: \mathrm{LaPO}_{4}(\mathrm{RE}=\mathrm{Eu}, \mathrm{Tb}$, Dy, Ce) Phosphors. J. Phys. Chem. C 2012, 116, 12854-1286o. (b) Song, W.S.; Lee, K.-H.; Do, Y. R.; Yang, H. Utilization of All Hydrothermally Synthesized Red, Green, Blue Nanophosphors for Fabrication of Highly Transparent Monochromatic and Full-Color Plasma Display Devices. Adv. Funct. Mater. 2012, 22, 1885-1893. (c) Malavasi, L.; Fisher, C. A. J.; Islam, M. S. Oxide-ion and proton conducting electrolyte materials for clean energy applications: structural and mechanistic features. Chem. Soc. Rev. 2o10, 39, 4370-4387. (d) Davis, J. B.; Marshall, D. B.; Morgan, P. E. D. Monazite-containing oxide/oxide composites. J. Eur. Ceram. Soc. 20oo, 20, 583-587. (e) Anfimova, T.; Li, Q.; Jensen, J. O.; Bjerrum, N. J. Thermal stability and proton conductivity of rare earth orthophosphate hydrates. Int. J. Electrochem. Sci. 2014, 9, 22852300. (f) Liu, C.; Hou, Y.; Gao, M. Are Rare-Earth Nanoparticles Suitable for In Vivo Applications? Adv. Mater. 2014, 26, 6922-6932. (g) Meiser, F.; Cortez, C.; Caruso, F. Biofunctionalization of Fluorescent Rare-Earth-Doped Lanthanum Phosphate Colloidal Nanoparticles. Angew. Chem. Int. Ed. 2004, 43, 5954-5957. (h) Rao, R. P.; Devine, D. J. RE-activated lanthanide phosphate phosphors for PDP applications. J. Lumin. 200o, 87-89, 1260-1263.

10. (a) Hikichi, Y.; Nomura, T. Melting Temperatures of Monazite and Xenotime. J. Am. Ceram. Soc. 1987, 70, C-252-C-253. (b) Cinibulk, M. K.; Fair, G. E.; Kerans, R. J. High-Temperature Stability of Lanthanum Orthophosphate (Monazite) on Silicon Carbide at Low Oxygen Partial Pressures. J. Am. Ceram. Soc. 2008, 91, 2290-2297.

11. Onoda, H.; Tange, K.; Tanaka, I. Influence of lanthanum addition on preparation and powder properties of cobalt phosphates. J. Mater. Sci. 2008, 43, 5483-5488.

12. Du, A.; Wan, C.; Qu, Z.; Pan, W. Thermal Conductivity of Monazite-Type $\mathrm{REPO}_{4}$ (RE=La, Ce, Nd, Sm, Eu, Gd). J. Am. Ceram. Soc. 2009, 92, 2687-2692.

13. Ghosh, P.; Oliva, J.; Rosa, E. D. 1.; Haldar, K. K.; Solis, D.; Patra, A. Enhancement of Upconversion Emission of $\mathrm{LaPO}_{4}:$ Er@Yb Core-Shell Nanoparticles/Nanorods. J. Phys. Chem. C 20o8, 112, 9650-9658.

14. Firsching, F. H.; Brune, S. N. Solubility products of the trivalent rare-earth phosphates. J. Chem. Eng. Data 1991, 36, 93-95.

15. Sankar, S.; Nair, B. N.; Suzuki, T.; Anilkumar, G. M.; Padmanabhan, M.; Hareesh, U. N. S.; Warrier, K. G. Hydrophobic and Metallophobic Surfaces: Highly Stable Non-wetting Inorganic Surfaces Based on Lanthanum Phosphate Nanorods. Sci. Rep. 2016, 6, 22732.

16. Boakye, E. E.; Mogilevsky, P.; Hay, R. S.; Fair, G. E. Synthesis and Phase Composition of Lanthanide Phosphate Nanoparticles $\mathrm{LnPO}_{4}$ ( $\mathrm{Ln}=\mathrm{La}, \mathrm{Gd}, \mathrm{Tb}, \mathrm{Dy}, \mathrm{Y}$ ) and Solid Solutions for Fiber Coatings. J. Am. Ceram. Soc. 2008, 91, 3841-3849.

17. Onoda, H.; Nariai, H.; Moriwaki, A.; Maki, H.; Motooka, I. Formation and catalytic characterization of various rare earth phosphates. J. Mater. Chem. 2002, 12, 1754-176o.

18. (a) Kitamura, N.; Amezawa, K.; Tomii, Y.; Yamamoto, N. Protonic conduction in rare earth orthophosphates with the monazite structure. Solid State Ionics 2oo3, 162-163, 161-165. (b) Amezawa, K.; Tomii, Y.; Yamamoto, N. High temperature protonic conduction in $\mathrm{LaPO}_{4}$ doped with alkaline earth metals. Solid State Ionics 2005, 176, 135-141. 
19. (a) Riwotzki, K.; Meyssamy, H.; Schnablegger, H.; Kornowski, A.; Haase, M. Liquid-Phase Synthesis of Colloids and Redispersible Powders of Strongly Luminescing $\mathrm{LaPO}_{4}: \mathrm{Ce}, \mathrm{Tb}$ Nanocrystals. Angew. Chem. Int. Ed. 2001, 40, 573-576. (b) Meyssamy, H.; Riwotzki, K.; Kornowski, A.; Naused, S.; Haase, M. Wet-Chemical Synthesis of Doped Colloidal Nanomaterials: Particles and Fibers of $\mathrm{LaPO}_{4}: \mathrm{Eu}$, $\mathrm{LaPO}_{4}: \mathrm{Ce}$, and $\mathrm{LaPO}_{4}: \mathrm{Ce}, \mathrm{Tb}$. Adv. Mater. 1999, 11, 840-844. (c) Buissette, V.; Moreau, M.; Gacoin, T.; Boilot, J.-P.; Chane-Ching, J.-Y.; Le Mercier, T. Colloidal Synthesis of Luminescent Rhabdophane $\mathrm{LaPO}_{4}: \mathrm{Ln}^{3+} \cdot \mathrm{xH}_{2} \mathrm{O}(\mathrm{Ln}=\mathrm{Ce}, \mathrm{Tb}, \mathrm{Eu} ; \mathrm{x} \approx 0.7)$ Nanocrystals. Chem. Mater. 2004, 16, 3767-3773.

20. (a) Feigelson, R. S. Synthesis and Single-Crystal Growth of RareEarth Orthophosphates. J. Am. Ceram. Soc. 1964, 47, 257-258. (b) Wang, X.; Gao, M. A facile route for preparing rhabdophane rare earth phosphate nanorods. J. Mater. Chem. 2006, 16, 1360-1365. (c) Bu, W.; Hua, Z.; Chen, H.; Shi, J. Epitaxial Synthesis of Uniform Cerium Phosphate One-Dimensional Nanocable Heterostructures with Improved Luminescence. J. Phys. Chem. B 2005, 109, 14461-14464. (d) Bao, J.; Yu, R.; Zhang, J.; Yang, X.; Wang, D.; Deng, J.; Chen, J.; Xing, $\mathrm{X}$. Low-temperature hydrothermal synthesis and structure control of nano-sized $\mathrm{CePO}_{4}$. CrystEngComm 2009, 11, 1630-1634. (e) Yan, R.; Sun, X.; Wang, X.; Peng, Q.; Li, Y. Crystal Structures, Anisotropic Growth, and Optical Properties: Controlled Synthesis of Lanthanide Orthophosphate One-Dimensional Nanomaterials. Chem. Eur. J. 2005, 11, 2183-2195. (f) Fang, Y.-P.; Xu, A.-W.; Song, R.-Q.; Zhang, H.X.; You, L.-P.; Yu, J. C.; Liu, H.-Q. Systematic Synthesis and Characterization of Single-Crystal Lanthanide Orthophosphate Nanowires. J. Am. Chem. Soc. 2003, 125, 16025-16034.

21. Murugavel, R.; Choudhury, A.; Walawalkar, M. G.; Pothiraja, R.; Rao, C. N. R. Metal Complexes of Organophosphate Esters and OpenFramework Metal Phosphates: Synthesis, Structure, Transformations, and Applications. Chem. Rev. 2oo8, 108, 3549-3655.

22. (a) Gupta, S. K.; Kuppuswamy, S.; Walsh, J. P. S.; McInnes, E. J. L.; Murugavel, R. Discrete and polymeric cobalt organophosphates: isolation of a 3-D cobalt phosphate framework exhibiting selective CO2 capture. Dalton Trans. 2o15, 44, 5587-56o1. (b) Murugavel, R.; Kuppuswamy, S.; Boomishankar, R.; Steiner, A. Hierarchical Structures Built from a Molecular Zinc Phosphate Core. Angew. Chem. Int. Ed. 2006, 45, 5536-5540. (c) Kalita, A. C.; Gupta, S. K.; Murugavel, R. A Solvent Switch for the Stabilization of Multiple Hemiacetals on an Inorganic Platform: Role of Supramolecular Interactions. Chem. Eur. J. 2016, 22, 6863-6875. (d) Van Allsburg, K. M.; Anzenberg, E.; Drisdell, W. S.; Yano, J.; Tilley, T. D. Oxygen-Atom Transfer Chemistry and Thermolytic Properties of a Di-tert-Butylphosphate-Ligated $\mathrm{Mn}_{4} \mathrm{O}_{4}$ Cubane. Chem. Eur. J. 2015, 21, 4646-4654. (e) Ahn, H. S.; Tilley, T. D. Electrocatalytic Water Oxidation at Neutral $\mathrm{pH}$ by a Nanostructured $\mathrm{Co}\left(\mathrm{PO}_{3}\right)_{2}$ Anode. Adv. Funct. Mater. 2013, 23, 227-233. (f) Dar, A. A.; Sen, S.; Gupta, S. K.; Patwari, G. N.; Murugavel, R. Octanuclear Zinc Phosphates with Hitherto Unknown Cluster Architectures: Ancillary Ligand and Solvent Assisted Structural Transformations Thereof. Inorg. Chem. 2015, 54, 9458-9469. (g) Murugavel, R.; Kuppuswamy, S.; Gogoi, N.; Steiner, A.; Bacsa, J.; Boomishankar, R.; Suresh, K. G. Controlling the Structure of Manganese(II) Phosphates by the Choice and Ratio of Organophosphate and Auxiliary Ligands. Chemistry - An Asian Journal 2009, 4, 143-153.

23. (a) Murugavel, R.; Walawalkar, M. G.; Dan, M.; Roesky, H. W.; Rao, C. N. R. Transformations of Molecules and Secondary Building Units to Materials: A Bottom-Up Approach. Acc. Chem. Res. 2004, 37, 763-774. (b) Murugavel, R.; Gogoi, N.; Suresh, K. G.; Layek, S.; Verma, H. C. Nuclearity Control in Molecular Iron Phosphates through Choice of Iron Precursors and Ancillary Ligands. Chem. Asian J. 2009, 4, 923-935. (c) Murugavel, R.; Kuppuswamy, S.; Maity, A. N.; Singh, M. P. Di-, Tri-, Tetra-, and Hexanuclear Copper(II) Monoorganophosphates: Structure and Nuclearity Dependence on the Choice of Phosphorus Substituents and Auxiliary N-Donor Ligands. Inorg. Chem. 2009, 48, 183-192.
24. (a) Nash, K. L.; Choppin, G. R. Separations Chemistry for Actinide Elements: Recent Developments and Historical Perspective. Sep. Sci. Technol. 1997, 32, 255-274. (b) Sood, D. D.; Patil, S. K. Chemistry of nuclear fuel reprocessing: Current status. J. Radioanal. Nucl. Chem. 1996, 203, 547-573. (c) Cocalia, V. A.; Jensen, M. P.; Holbrey, J. D.; Spear, S. K.; Stepinski, D. C.; Rogers, R. D. Identical extraction behavior and coordination of trivalent or hexavalent f-element cations using ionic liquid and molecular solvents. Dalton Trans. 2005, 19661971. (d) Paiva, A. P.; Malik, P. Recent advances on the chemistry of solvent extraction applied to the reprocessing of spent nuclear fuels and radioactive wastes. J. Radioanal. Nucl. Chem. 2004, 261, 485-496. (e) Warf, J. C. Extraction of Cerium(IV) Nitrate by Butyl Phosphate. J. Am. Chem. Soc. 1949, 71, 3257-3258.

25. (a) Nifant'ev, I. E.; Tavtorkin, A. N.; Shlyahtin, A. V.; Korchagina, S. y. A.; Gavrilenko, I. F.; Glebova, N. N.; Churakov, A. V. Easily accessible, hydrocarbon-soluble, crystalline, anhydrous lanthanide (Nd, La, and Y) phosphates. Dalton Trans. 2013, 42, 1223-1230. (b) Lisowski, J.; Sessler, J. L.; Lynch, V.; Mody, T. D. 1 H NMR Spectroscopic Study of Paramagnetic Lanthanide(III) Texaphyrins. Effect of Axial Ligation. J. Am. Chem. Soc. 1995, 117, 2273-2285. (c) Zeng, G.; Guo, X.; Wang, C.; Lin, Y.; Li, H. Crystal structure of tris(dimethyl phosphato)lanthanum(III) coordination polymer $\left\{\mathrm{La}\left[\mathrm{PO}_{2}\left(\mathrm{OCH}_{3}\right)_{2}\right]_{3}\right\}_{\mathrm{n}}$. Jiegou Huaxue 1994, 3, 24. (d) Li, L.; Lin, Y.; Zeng, G.; Ma, A. Synthesis and crystal structure of complex of samarium with dimethyl phosphate. Yingyong Huaxue 1989, 6, 53-57. (e) Li, L.; Lin, Y.; Zeng, G.; Ma, A. Synthesis and crystal structure of tris(dimethyl phosphate)europium. Jiegou Huaxue 1991, 10, 155-158. (f) Ma, A.; Li, L.; Lin, Y.; Zeng, G.; Li, H. Synthesis and structural study of praseodymium-dimethyl phosphate complex. Zhongguo Xitu Xuebao 1990, 8, 201-2014. (g) Liu, C.; Wu, G.; Tang, Z.; Han, Y.; Pan, Z.; Shi, N.; Liao, L. Synthesis and crystal structure of lanthanum dimethyl phosphate monohydrate. 1990, 48, 116-120. (h) Ma, A.; Li, L.; Lin, Y.; Zeng, G.; Jin, S.; Li, H. Synthesis and crystal structure of lanthanum complex with tris(dimethyl phosphate) and trimethyl phosphate. Yingyong Huaxue 1989, 6, 99-103. (i) Han, Y.; Pan, Z.; Shi, N.; Liao, L.; Liu, C.; Wu, G.; Tang, Z.; Xiao, Y. Crystal structures of cerium and praseodymium diethylphosphates. Wuji Huaxue Xuebao 199o, 6, 1724. (j) Huang, C.; Yi, T.; Lu, Y.; Xu, G.; Ling, H.; Ma, Z. Crystal structures of cerium and praseodymium diethylphosphates. Chin. Chem. Lett. 1992, 3, 947-950. (k) Lebedev, V. G.; Palkina, K. K.; Maksimova, S. I.; Lebedeva, E. N.; Galaktionova, O. V. Z. Synthesis and structure of tris(diethyl phosphate)neodymium crystals. Z. Neorg. Khim. 1982, 27, 2980-2982.

26. (a) Mokry, L. M.; Dean, N. S.; Carrano, C. J. Synthesis and Structure of a Discrete Hexanuclear Uranium-Phosphate Complex. Angew. Chem. Int. Ed. Engl. 1996, 35, 1497-1498. (b) Burns, J. H. Solvent-extraction complexes of the uranyl ion. 2. Crystal and molecular structures of catena-bis( $\mu$-di-n-butyl phosphato$\left.\mathrm{O}, \mathrm{O}^{\prime}\right)$ dioxouranium $(\mathrm{VI})$ and bis( $\mu$-di-n-butyl phosphato$\left.\mathrm{O}, \mathrm{O}^{\prime}\right)$ bis [(nitrato)(tri-n-butylphosphine oxide)dioxouranium(VI)] Inorg. Chem. 1983, 22, 1174-1178. (c) Kanellakopulos, B.; Dernberger, E.; Maier, R.; Nuber, B.; Stammler, H.-G.; Ziegler, M. L. Molecular structure and charge distribution. IV. Electric dipole moment of the 1:2 adducts of uranyl nitrate with trialkyl phosphates. The crystal structure of $\mathrm{UO}_{2}(\mathrm{TEP})_{2}\left(\mathrm{NO}_{3}\right)_{2}$ and bis[(m-diethyl phosphato$\left.\mathrm{O}, \mathrm{O}^{\prime}\right)$ nitrato(triethyl phosphate)dioxouranium(VI)], $\left\{\left(\mathrm{UO}_{2}\right)\left[(\mathrm{EtO})_{2} \mathrm{PO}_{2}\right]\left[(\mathrm{EtO})_{3} \mathrm{PO}\right]\left(\mathrm{NO}_{3}\right)\right\}_{2}$. Z. Anorg. Allg. Chem. 1993, 619, 593-60o.

27. (a) Zheng, Y.-Z.; Evangelisti, M.; Tuna, F.; Winpenny, R. E. P. CoLn Mixed-Metal Phosphonate Grids and Cages as Molecular Magnetic Refrigerants. J. Am. Chem. Soc. 2012, 134, 1057-1065. (b) Sheikh, J. A.; Clearfield, A. Heterometallic CoIII-GdIII Clusters as Magnetic Refrigerants. Inorg. Chem. 2016, 55, 8254-8256. (c) Zheng, Y.-Z.; Pineda, E. M.; Helliwell, M.; Winpenny, R. E. P. Mn ${ }^{\text {II }-G d^{I I I}}$ Phosphonate Cages with a Large Magnetocaloric Effect. Chem. Eur. J. 2012, 18, 4161-4165. (d) Tang, X.; Xu, Y.; Ye, W.; Tang, Y.; Ma, Y.; Yuan, R. $\mathrm{Mn}(\mathrm{II})_{2} \mathrm{Gd}(\mathrm{III})_{3}$ Phosphonate as a Molecular Refrigerant. Aust. J. Chem. 2015, 68, 1926-1928. (e) Moreno Pineda, E.; Tuna, F.; Pritchard, 
R. G.; Regan, A. C.; Winpenny, R. E. P.; McInnes, E. J. L. Molecular amino-phosphonate cobalt-lanthanide clusters. Chem. Commun. 2013, 49, 3522-3524. (f) Tang, X.; Zhong, Q.; Xu, J.; Li, H.; Xu, S.; Cui, X.; Wei, B.; Ma, Y.; Yuan, R. Co(II) ${ }_{4} \mathrm{Gd}(\mathrm{III})_{6}$ phosphonate grid and cage as molecular refrigerants. Inorg. Chim. Acta 2016, 442, 195-199. (g) Pineda, E. M.; Tuna, F.; Zheng, Y.-Z.; Winpenny, R. E. P.; McInnes, E. J. L. Wells-Dawson Cages as Molecular Refrigerants. Inorg. Chem. 2013, 52, 13702-13707.

28. (a) Ragunathan, K. G.; Schneider, H.-J. Binuclear Lanthanide Complexes as Catalysts for the Hydrolysis of Bis(p-nitrophenyl)phosphate and Double-Stranded DNA. Angew. Chem. Int. Ed. Engl. 1996, 35, 1219-1221. (b) Yoo, B.; Pagel, M. Lanthanide-Mediated Dephosphorylation Used for Peptide Cleavage during Solid Phase Peptide Synthesis. Molecules 2013, 18, 3894. (c) Aguilar-Pérez, F.; Gómez-Tagle, P.; Collado-Fregoso, E.; Yatsimirsky, A. K. Phosphate Ester Hydrolysis by Hydroxo Complexes of Trivalent Lanthanides Stabilized by 4-Imidazolecarboxylate. Inorg. Chem. 2006, 45, 95029517. (d) Roigk, A.; Yescheulova, O. V.; Fedorov, Y. V.; Fedorova, O. A.; Gromov, S. P.; Schneider, H.-J. Carboxylic Groups as Cofactors in the Lanthanide-Catalyzed Hydrolysis of Phosphate Esters. Stabilities of Europium(III) Complexes with Aza-benzo-15-crown-5 Ether Derivatives and Their Catalytic Activity vs Bis(pnitrophenyl)phosphate and DNA. Org. Lett. 1999, 1, 833-835. (e) Roigk, A.; Hettich, R.; Schneider, H.-J. Unusual Catalyst Concentration Effects in the Hydrolysis of Phenyl Phosphate Esters and of DNA: A Systematic Investigation of the Lanthanide Series1. Inorg. Chem. 1998, 37, 751-756.

29. (a) Murugavel, R.; Gogoi, N.; Clérac, R. Tetra- and Decanuclear Iron(III) Phosphonates: Observance of a Rare P-C Bond Cleavage in a Homogeneous Medium. Inorg. Chem. 2oo9, 48, 646-651. (b) Goura, J.; Walsh, J. P. S.; Tuna, F.; Halder, R.; Maji, T. K.; Chandrasekhar, V. PC Bond Cleavage-Assisted Lanthanide Phosphate Coordination Polymers. Cryst. Growth Des. 2015, 15, 2555-2560.

30. (a) Li, X.; Sun, H.-L.; Wu, X.-S.; Qiu, X.; Du, M. Unique (3,12)Connected Porous Lanthanide-Organic Frameworks Based on $\mathrm{Ln}_{4} \mathrm{O}_{4}$ Clusters: Synthesis, Crystal Structures, Luminescence, and Magnetism. Inorg. Chem. 2010, 49, 1865-1871. (b) Baskar, V.; Roesky, P. W. Lanthanide hydroxide cubane clusters anchoring ferrocenes: model compounds for fixation of organometallic fragments on a lanthanide oxide surface. Dalton Trans. 2oo6, 676-679. (c) Zhou, J.M.; Shi, W.; Li, H.-M.; Li, H.; Cheng, P. Experimental Studies and Mechanism Analysis of High-Sensitivity Luminescent Sensing of Pollutional Small Molecules and Ions in $\mathrm{Ln}_{4} \mathrm{O}_{4}$ Cluster Based Microporous Metal-Organic Frameworks. J. Phys. Chem. C 2014, 118, 416-426. (d) Ma, B.-Q.; Zhang, D.-S.; Gao, S.; Jin, T.-Z.; Yan, C.-H.; Xu, G.-X. From Cubane to Supercubane: The Design, Synthesis, and Structure of a Three-Dimensional Open Framework Based on a $\mathrm{Ln}_{4} \mathrm{O}_{4}$ Cluster. Angew. Chem. 200o, 112, 3790-3792.

31. Coxall, R. A.; Harris, S. G.; Henderson, D. K.; Parsons, S.; Tasker, P. A.; Winpenny, R. E. P. Inter-ligand reactions: in situ formation of new polydentate ligands. Journal of the Chemical Society, Dalton Transactions 2000, 2349-2356.

32. Llunell, M.; Casanova, D.; Cirera, J.; Bofill, J.; Alemany, P.; Alvarez, S. SHAPE (Version 2.1), Barcelona, 2013.

33. (a) Chakraborty, J.; Ray, A.; Pilet, G.; Chastanet, G.; Luneau, D.; Ziessel, R. F.; Charbonniere, L. J.; Carrella, L.; Rentschler, E.; El Fallah, M. S.; Mitra, S. Syntheses, characterisation, magnetism and photoluminescence of a homodinuclear Ln(III)-Schiff base family. Dalton Trans. 2009, 10263-10272. (b) Zhao, L.; Lin, S.; Shen, S.; Tang, J. A novel two dimensional samarium(III) coordination framework with $\mathrm{N}$-(2-Hydroxyethyl)iminodiacetic acid and oxalate ligands: Synthesis, crystal structure and magnetic property. Inorg. Chem. Commun. 2011, 14, 1928-1931. (c) Yang, X.-D.; Zhang, C.-H.; Wang, D.P.; Chen, Y.-G. A new $2 \mathrm{D}$ network constructed by polymeric anions and lanthanides. Synthesis, structure and magnetic property of two new compounds. Inorg. Chem. Commun. 2010, 13, 1350-1353.

34. (a) Ge, J.-Y.; Ru, J.; Gao, F.; Song, Y.; Zhou, X.-H.; Zuo, J.-L. Pentanuclear lanthanide pyramids based on thiacalix[4]arene ligand exhibiting slow magnetic relaxation. Dalton Trans. 2015, 44, 1548115490. (b) Gamer, M. T.; Lan, Y.; Roesky, P. W.; Powell, A. K.; Clérac, R. Pentanuclear Dysprosium Hydroxy Cluster Showing SingleMolecule-Magnet Behavior. Inorg. Chem. 2oo8, 47, 6581-6583. (c) Andrews, P. C.; Beck, T.; Fraser, B. H.; Junk, P. C.; Massi, M.; Moubaraki, B.; Murray, K. S.; Silberstein, M. Functionalised $\beta$ diketonate polynuclear lanthanoid hydroxo clusters: Synthesis, characterisation, and magnetic properties. Polyhedron 2009, 28, 21232130. (d) Zhang, Z.; Zhang, Y.; Zheng, Z. In Recent Development in Clusters of Rare Earths and Actinides: Chemistry and Materials; Zheng, Z., Ed.; Springer Berlin Heidelberg: Berlin, Heidelberg, 2017; pp 1-49. 35. (a) Chibotaru, L. F.; Ungur, L.; Soncini, A. The Origin of Nonmagnetic Kramers Doublets in the Ground State of Dysprosium Triangles: Evidence for a Toroidal Magnetic Moment. Angew. Chem. Int. Ed. 20o8, 47, 4126-4129. (b) Li, X.-L.; Wu, J.; Tang, J.; Le Guennic, B.; Shi, W.; Cheng, P. A planar triangular $\mathrm{Dy}_{3}+\mathrm{Dy}_{3}$ single-molecule magnet with a toroidal magnetic moment. Chem. Commun. 2016, 52, 9570-9573.

36. Armarego, W. L. F.; Perrin, D. D. Purification of laboratory chemicals, Butterworth Heinemann, Oxford, Boston 1996.

37. Kosolapoff, G. M.; Arpke, C. K.; Lamb, R. W.; Reich, H. Structural effects in reactions of organophosphorus compounds. I. Reactions of phosphorus oxychloride with hindered phenols. J. Chem. Soc. C 1968, 815-818.

38. CrystalClear, V.-S. E. r., 2009 and CrystalStructure, Version 4.o. Rigaku, 2010

39. Altomare, A.; Burla, M. C.; Camalli, M.; Cascarano, G. L.; Giacovazzo, C.; Guagliardi, A.; Moliterni, A. G. G.; Polidori, G.; Spagna, R. SIR97: a new tool for crystal structure determination and refinement. J. Appl. Crystallogr. 1999, 32, 115-119.

40. Farrugia, L. WinGX and ORTEP for Windows: an update. J. Appl. Crystallogr. 2012, 45, 849-854.

41. Sheldrick, G. Crystal structure refinement with SHELXL. Acta Crystallographica Section C 2015, 71, 3-8.

42. Spek, A. Single-crystal structure validation with the program PLATON. J. Appl. Crystallogr. 2003, 36, 7-13. 
Table 5. Data Collection and Structure Refinement details for 1-5.

\begin{tabular}{|c|c|c|c|c|}
\hline Compound & 1 & 2 & 3 & 5 \\
\hline $\mathrm{CCDC}$ & 1520605 & 1520606 & 1520607 & 1520608 \\
\hline Identification code & $\mathrm{SKG}_{420}$ & $\mathrm{SKG}_{421}$ & $\mathrm{SKG}_{424}$ & SKG546R \\
\hline Empirical Formula & $\mathrm{C}_{83} \mathrm{H}_{157} \mathrm{~N}_{2} \mathrm{Nd}_{5} \mathrm{O}_{47} \mathrm{P}_{6}$ & $\mathrm{C}_{84} \mathrm{H}_{159} \mathrm{Sm}_{5} \mathrm{~N}_{2} \mathrm{O}_{47} \mathrm{P}_{6}$ & $\mathrm{C}_{84} \mathrm{H}_{159} \mathrm{Eu}_{5} \mathrm{~N}_{2} \mathrm{O}_{47} \mathrm{P}_{6}$ & $\mathrm{C}_{83} \mathrm{H}_{157} \mathrm{~N}_{2} \mathrm{O}_{47} \mathrm{P}_{6} \mathrm{~Tb}_{5}$ \\
\hline Temp. (K) & $150(2)$ & $150(2)$ & $150(2)$ & $150(2)$ \\
\hline Crystal system & Triclinic & Triclinic & Triclinic & Triclinic \\
\hline Space group & $P-1$ & $P-1$ & $P-1$ & $P-1$ \\
\hline $\mathrm{a}(\AA ̊)$ & $14.219(2)$ & $14.157(2)$ & $14.125(3)$ & $14.124(2)$ \\
\hline $\mathrm{b}(\AA)$ & $17.081(3)$ & $17.015(3)$ & $16.970(4)$ & $16.848(3)$ \\
\hline c $(\AA)$ & $25.463(4)$ & $25 \cdot 380(4)$ & $25 \cdot 374(5)$ & $25.418(4)$ \\
\hline$\alpha\left(^{\circ}\right)$ & $99 \cdot 330(2)$ & $99 \cdot 338(3)$ & $99.462(3)$ & $99.442(3)$ \\
\hline$\beta\left(^{\circ}\right)$ & $90.523(3)$ & $90.6540(10)$ & $90.702(3)$ & $90.785(3)$ \\
\hline$\gamma\left(^{\circ}\right)$ & 105.789(3) & $105.732(4)$ & $105.645(4)$ & $105.199(3)$ \\
\hline Volume $\left(\AA^{3}\right)$ & $5863.0(16)$ & $5796.7(16)$ & $5767(2)$ & $5747.6(16)$ \\
\hline $\mathrm{Z}$ & 2 & 2 & 2 & 2 \\
\hline$\mu\left(\mathrm{mm}^{-1}\right)$ & 2.339 & 2.660 & 2.847 & 3.208 \\
\hline Crystal size $\left(\mathrm{mm}^{3}\right)$ & $0.20 \times 0.18 \times 0.10$ & $0.12 \times 0.10 \times 0.04$ & $0.15 \times 0.13 \times 0.08$ & $0.24 \times 0.16 \times 0.16$ \\
\hline Reflections collected & 43876 & 43224 & 43281 & 42877 \\
\hline Independent reflections & $20432[\mathrm{R}($ int $)=0.0378]$ & $20130[\mathrm{R}(\mathrm{int})=0.0304]$ & $20070[\mathrm{R}($ int $)=0.0250]$ & $19999[\mathrm{R}(\mathrm{int})=0.0275]$ \\
\hline Data / restraints / parameters & $20432 / 22 / 1309$ & $20130 / 34 / 1344$ & $20070 / 19 / 1381$ & 19999 / 1394 / 1398 \\
\hline Goodness-of-fit on $\mathrm{F}^{2}$ & 1.073 & 1.124 & 1.076 & 1.128 \\
\hline Final $\mathrm{R}$ indices [I>2sigma(I)] & $\mathrm{R} 1=0.0479, \mathrm{wR2}=0.117 \mathrm{O}$ & $\mathrm{R} 1=0.0425, \mathrm{wR} 2=0.0956$ & $\mathrm{R} 1=0.0316, \mathrm{wR2}=0.0780$ & $\mathrm{R} 1=0.0424, \mathrm{wR2}=0.1034$ \\
\hline $\mathrm{R}$ indices (all data) & $\mathrm{R} 1=0.0493, \mathrm{wR} 2=0.1181$ & $\mathrm{R} 1=0.0440, \mathrm{wR} 2=0.0968$ & $\mathrm{R} 1=0.0326, \mathrm{wR} 2=0.0787$ & $\mathrm{R}_{1}=0.0432, \mathrm{wR} 2=0.1039$ \\
\hline Largest diff. peak and hole (e. $\left.\AA^{-3}\right)$ & 3.377 and -2.940 & 2.968 and -1.902 & 2.525 and -1.356 & 3.664 and -2.159 \\
\hline
\end{tabular}

Table 6. Data Collection and Structure Refinement details for 6-9.

\begin{tabular}{|c|c|c|c|c|}
\hline Compound & 6 & 7 & 8 & 9 \\
\hline CCDC & 1520609 & 1520610 & 1520611 & 1520612 \\
\hline Identification code & $\mathrm{SKG}_{422}$ & $\mathrm{SKG}_{586}$ & $\mathrm{SKG}_{427}$ & SKG620 \\
\hline Empirical Formula & $\mathrm{C}_{85} \mathrm{H}_{160} \mathrm{Dy}_{5} \mathrm{~N}_{4} \mathrm{O}_{48} \mathrm{P}_{6}$ & $\mathrm{C}_{85} \mathrm{H}_{160} \mathrm{Ho}_{5} \mathrm{~N}_{4} \mathrm{O}_{48} \mathrm{P}_{6}$ & $\mathrm{C}_{85} \mathrm{H}_{160} \mathrm{Er}_{5} \mathrm{~N}_{4} \mathrm{O}_{48} \mathrm{P}_{6}$ & $\mathrm{C}_{96} \mathrm{H}_{178} \mathrm{O}_{46} \mathrm{P}_{7} \mathrm{Tm}_{5}$ \\
\hline Temp. (K) & $150(2)$ & $150(2)$ & $150(2)$ & $150(2)$ \\
\hline Crystal system & Triclinic & Triclinic & Triclinic & Monoclinic \\
\hline Space group & $P-1$ & $P-1$ & $P-1$ & $P_{2_{1} / n}$ \\
\hline $\mathrm{a}(\AA)$ & $15.213(2)$ & $15.264(4)$ & $15.253(3)$ & $14.8572(16)$ \\
\hline $\mathrm{b}(\AA)$ & $15.987(2)$ & $15.993(4)$ & 16.025(3) & $34.890(4)$ \\
\hline c $(\AA)$ & 26.093(4) & $26.040(6)$ & $26.013(5)$ & $24.726(3)$ \\
\hline$\alpha\left(^{\circ}\right)$ & $94.125(2)$ & $93.585(4)$ & 93.779(3) & 90 \\
\hline$\beta\left(^{\circ}\right)$ & 99.124(3) & $99.456(3)$ & $99.260(2)$ & $90.716(2)$ \\
\hline$\gamma\left({ }^{\circ}\right)$ & $106.545(2)$ & $106.490(3)$ & $106.619(2)$ & 90 \\
\hline Volume $\left(\AA^{3}\right)$ & $5960.2(14)$ & $5972(3)$ & $5971(2)$ & $12816(3)$ \\
\hline $\mathrm{Z}$ & 2 & 2 & 2 & 4 \\
\hline$\mu\left(\mathrm{mm}^{-1}\right)$ & 3.261 & 3.438 & 3.640 & 3.586 \\
\hline Crystal size $\left(\mathrm{mm}^{3}\right)$ & $0.21 \times 0.19 \times 0.13$ & $0.13 \times 0.12 \times 0.07$ & $0.15 \times 0.10 \times 0.08$ & $0.20 \times 0.20 \times 0.16$ \\
\hline Reflections collected & 44056 & 44551 & 44898 & 76915 \\
\hline Independent reflections & $20642[\mathrm{R}(\mathrm{int})=0.026 \mathrm{o}]$ & $20667[\mathrm{R}(\mathrm{int})=0.0398]$ & $20785[\mathrm{R}(\mathrm{int})=0.0326]$ & $22993[\mathrm{R}($ int $)=0.0912]$ \\
\hline Data / restraints / parameters & $20642 / 21 / 1426$ & $20667 / 32 / 1432$ & $20785 / 18 / 1410$ & $22993 / 51 / 1388$ \\
\hline Goodness-of-fit on $\mathrm{F}^{2}$ & 1.07 & 1.115 & 1.0069 & 1.105 \\
\hline Final $\mathrm{R}$ indices [I>2sigma $(\mathrm{I})]$ & $\mathrm{R} 1=0.0298, \mathrm{wR} 2=0.0737$ & $\mathrm{R} 1=0.0412, \mathrm{wR} 2=0.0984$ & $\mathrm{R} 1=0.0384, \mathrm{wR2}=0.0911$ & $\mathrm{R} 1=0.0531, \mathrm{wR} 2=0.1263$ \\
\hline $\mathrm{R}$ indices (all data) & $\mathrm{R} 1=0.0309, \mathrm{wR2}=0.0747$ & $\mathrm{R} 1=0.0430, \mathrm{wR}_{2}=0.1004$ & $\mathrm{R}_{1}=0.0404, \mathrm{wR} 2=0.0929$ & $\mathrm{R} 1=0.0656, \mathrm{wR} 2=0.1291$ \\
\hline Largest diff. peak and hole (e. $\left.\AA^{-3}\right)$ & 1.815 and -2.053 & 1.627 and -2.108 & 2.185 and -1.405 & 1.822 and -1.155 \\
\hline
\end{tabular}




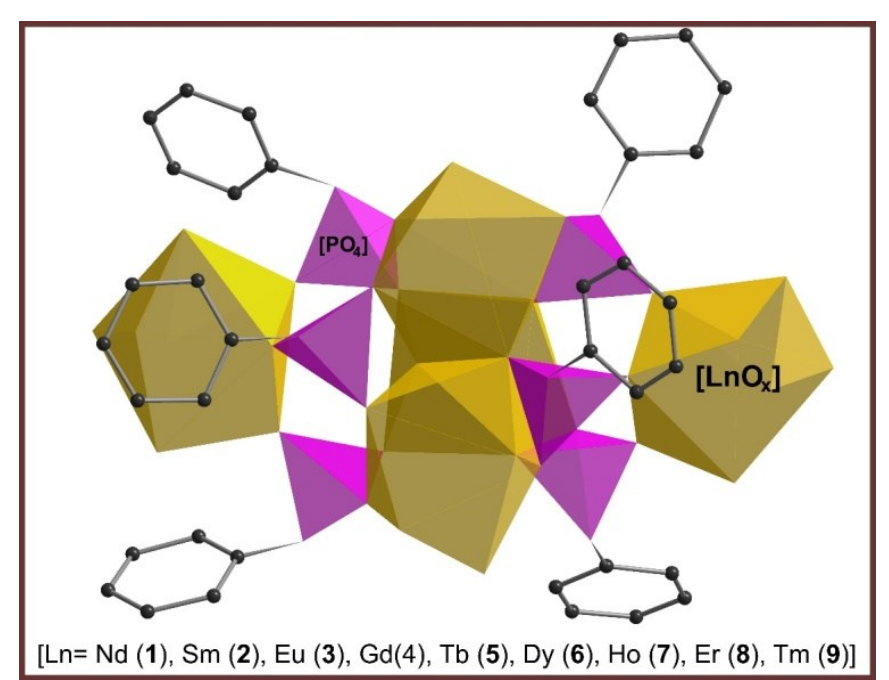

The present study describes a series of primary structurally characterized pentanuclear rare-earth organophosphates $\left[\mathrm{Ln}_{5}\left(\mu_{3}-\mathrm{OH}\right)(\operatorname{dipp})_{6}\left(\mathrm{CH}_{3} \mathrm{OH}\right)_{x}\left(\mathrm{H}_{2} \mathrm{O}\right)_{\mathrm{y}}\right]^{2+}[\mathrm{Ln}=\mathrm{Nd}(\mathbf{1}), \mathrm{Sm}(\mathbf{2}), \mathrm{Eu}(\mathbf{3}), \mathrm{Gd}(\mathbf{4}), \mathrm{Tb}(\mathbf{5}), \mathrm{Dy}(\mathbf{6}), \mathrm{Ho}(\mathbf{7}), \mathrm{Er}(\mathbf{8}), \mathrm{Tm}(\mathbf{9})]$ assembled from a sterically encumbered mono-ester of phosphoric acid under mild reaction conditions. The magnetic properties are described. Insights into the structure make the effect of the lanthanide contraction evident from the reduction in the coordination number around $\mathrm{Ln}$ ions and shortening of $\mathrm{Ln}-\mathrm{O}$ bonds. 